\title{
Contagion of self-fulfilling financial crises due to diversification of investment portfolios
}

\author{
Itay Goldstein ${ }^{\mathrm{a}, *}$ and Ady Pauzner ${ }^{\mathrm{b}}$ \\ ${ }^{a}$ Fuqua School of Business, Duke University, Box 90120, Durham NC 27708, USA \\ ${ }^{\mathrm{b}}$ The Eitan Berglas School of Economics, Tel Aviv University, Israel
}

Received 9 December 2003; final version received 29 March 2004

Available online 2 July 2004

\begin{abstract}
We look at two countries that have independent fundamentals, but share the same group of investors. Each country might face a self-fulfilling crisis: Agents withdrawing their investments fearing that others will. A crisis in one country reduces agents' wealth. This makes them more averse to the strategic risk associated with the unknown behavior of other agents in the second country, increasing their incentive to withdraw their investments. Consequently, the probability of a crisis there increases. This generates a positive correlation between the returns in the two countries. Since diversification affects returns in our model, its welfare implications are non-trivial.
\end{abstract}

(C) 2004 Elsevier Inc. All rights reserved.

JEL classification: G15; E32; D84

Keywords: Financial crises; Contagion; Global games; Diversification; Globalization; Coordination failures; Capital controls; Wealth effect; Strategic risk

\section{Introduction}

In recent years, financial markets have become increasingly open to international capital flows. ${ }^{1}$ This process of globalization is usually praised for creating opportunities to diversify investment portfolios. At the same time, the financial world has witnessed a number of cases in which financial crises spread from one

${ }^{*}$ Corresponding author. Fax: + 1-919-660-7971.

E-mail addresses: itayg@wharton.upenn.edu (I. Goldstein), pauzner@post.tau.ac.il (A. Pauzner).

${ }^{1}$ See, for example [2]. 
country to another. ${ }^{2}$ In some cases, crises spread even between countries which do not appear to have any common economic fundamentals.

In this paper, we present a model in which contagion of financial crises occurs precisely because investment portfolios are diversified across countries. The fact that different countries share the same group of investors leads to the transmission of negative shocks from one part of the world to another. Thus, the realization of a financial crisis in one country can induce a crisis in other countries as well. This generates a positive correlation between the returns on investments in different countries and thus reduces the effectiveness of diversifying investments across countries.

We focus on self-fulfilling crises: crises that occur just because agents believe they are going to occur. This is an important feature since financial crises are often viewed as the result of a coordination failure among economic agents. ${ }^{3}$ While recent literature has provided theoretical foundations for either the contagion of crises or for the possibility of self-fulfilling crises, models in which both co-exist have rarely been studied. The difficulty in demonstrating contagion in a model of self-fulfilling beliefs derives from the fact that such models are often characterized by multiple equilibrium outcomes. Since models with multiple equilibria do not predict the likelihood of each particular equilibrium, they cannot capture a contagion effect in which a crisis in one country affects the likelihood of a crisis in another.

To tackle this difficulty, we employ a technique introduced by Carlsson and vanDamme [6] which has recently been applied in a number of papers exploring financial crises. ${ }^{4}$ This technique allows us to determine the likelihood of each outcome and relate it to observable variables. We find that the likelihood of a crisis decreases with agents' wealth. Hence, the occurrence of a crisis in one country, which reduces this wealth, increases the likelihood of a self-fulfilling crisis in a second country.

Agents in our model hold investments in two countries. Investments can either be held to maturity, in which case returns are an increasing function of the fundamentals of the country and the number of agents who keep their investments there, ${ }^{5}$ or can be withdrawn prematurely for a fixed payoff. In most cases, if no one withdraws their investments in a certain country early, then each agent will obtain a higher return by keeping her investment in that country until it matures. But if all agents withdraw early, the long-term return is reduced to below the return for early withdrawal. As a result, agents might coordinate on withdrawing early in a country, even though they could obtain higher returns by coordinating on keeping their investments there until maturity. Agents' beliefs regarding the behavior of other agents in that country will determine whether there will be a financial crisis, i.e., a mass withdrawal of investments. ${ }^{6}$

\footnotetext{
${ }^{2}$ See, for example [24].

${ }^{3}$ See $[24,34]$ for a description of the recent crises in South East Asia, and [12,32] for models of selffulfilling financial crises.

${ }^{4}$ See, for example $[8,11,14,15,28,31,36]$, and two excellent surveys by Morris and Shin [29,30].

${ }^{5}$ This can be due, for example, to increasing returns to scale in aggregate investment or to liquidity constraints.

${ }^{6}$ This kind of financial crisis is similar to the one described by Diamond and Dybvig [12].
} 
We examine a sequential framework in which the events in country 2 take place after the aggregate outcomes in country 1 (which depend on fundamentals and the behavior of agents there) are realized and become known to all agents. Following Carlsson and van-Damme [6], we assume that agents do not have common knowledge of the fundamentals of country 2 , but rather get slightly noisy signals about them after they are realized. This can be due to agents having access to different sources of information or to slight differences in their interpretation of publicly available information. This structure of information enables us to uniquely determine the beliefs and behavior of agents in country 2 as a function of the fundamentals of country 2 and of the outcomes in country 1 . We show that agents will withdraw early in country 2 only if the fundamentals there are below a certain threshold. Importantly, this threshold level depends on the outcomes in country 1 . In most circumstances, the coordination of agents on withdrawing their investments in country 1 early increases the threshold and thus increases the probability of a crisis in country 2. We refer to this effect as 'contagion'.

The mechanism that generates contagion in our model originates in a wealth effect. In most cases, the occurrence of a crisis in country 1 reduces the wealth of agents. We assume that agents have decreasing absolute risk aversion. Thus, a crisis in country 1 makes them more risk averse when choosing their actions in country 2 . Since keeping their investments in country 2 is a risky action, agents will have weaker incentives to do so following a crisis in country 1.

It is important to note that the risk involved in keeping one's investment in country 2 does not result from the uncertainty about the level of the fundamentals in that country. This uncertainty is negligible since agents get rather precise signals about the level of these fundamentals. Rather, it is a strategic risk: a risk that results from the unknown behavior of other agents in country 2 . When an agent chooses to maintain her investment, her return depends on the actions of other agents. Thus, if she has less wealth, her incentive to withdraw early and obtain a return that does not depend on others' behavior is increased.

While strategic risk would appear to be an important factor in any situation involving strategic complementarities, such a risk is not captured in models that assume common knowledge of fundamentals. In these models, each agent is certain about the equilibrium behavior of other agents and thus strategic risk does not exist. In our model, an agent who observes a signal, which is close to the threshold at which agents switch actions, will be uncertain about the behavior of other agents. Thus, the change in wealth has a direct effect on her behavior. This has a considerable effect on the threshold signal below which agents withdraw their investments.

Having demonstrated the existence of contagion in our model, we then go on to analyze the behavior of agents in country 1 . We show that there exists an equilibrium in country 1 in which agents withdraw early in country 1 only if the realization of the fundamentals in that country is below a certain level. ${ }^{7}$ In this equilibrium, an endogenous positive correlation exists between the returns on investments in

\footnotetext{
${ }^{7}$ We are not, however, able to prove that this is the unique equilibrium in country 1.
} 
the two countries. When fundamentals in country 1 are low, a crisis occurs there and the return on investment is low. Following this, a crisis is more likely to occur in country 2 as well, implying a higher likelihood of obtaining a low return there also. It is important to note that this positive correlation is obtained even though we have assumed that the fundamentals of the two countries are completely independent of one another. Thus, the positive correlation can only be the result of the contagion effect, which is caused by the diversification of investment portfolios.

More generally, when an investor in our model diversifies her investments, she affects not only the variance of her portfolio's return, but the real economy as well. This is because diversification affects the thresholds below which financial crises occur, thus generating an indirect channel through which diversification affects investors' welfare. Since the investor is small, when she chooses the initial allocation of her portfolio she ignores this externality and takes the distribution of returns in each country as given. Since diversification reduces the variance of her portfolio, and since, in our model, it does not entail any direct cost, she will diversify her portfolio fully. The existence of an externality raises the natural question of whether full diversification is also optimal from a social point of view. And if it is not, could government intervention, that puts restrictions on diversification, be welfare improving?

We analyze these questions numerically. We show that the indirect channel through which diversification affects welfare consists of two different effects. The first is a result of the contagion effect described earlier. When the level of diversification increases, the correlation between the returns on investments in the two countries becomes stronger, and the benefit from diversification decreases. This represents a social cost of diversification. The second effect is independent of the contagion result. The tendency of agents to run in a given country depends on the proportion of wealth they hold in that country: when this proportion increases, they risk more by not running in that country, and thus have a stronger incentive to run. When agents from both countries are not allowed to fully diversify, then, in each country, local agents will have a higher proportion of their wealth at stake while foreign agents will have a lower proportion. Thus, the former will have a stronger tendency to run while the latter will have a weaker one; the overall effect on the probabilities of crises is therefore ambiguous. Combining the two indirect effects with the direct effect discussed earlier (by which diversification reduces the variance of the portfolio), we conclude that the overall effect of diversification on welfare in our model is ambiguous. This is in contrast to a model that considers only the direct effect, in which (costless) diversification unambiguously increases welfare. We present an example, in which partial diversification yields higher welfare than full diversification. In this example, capital controls imposed by the government may improve welfare.

The existence of an indirect channel through which diversification affects welfare may also lead to other policy implications. As we show in the paper, in some cases this indirect channel increases the overall benefit from diversification. In such cases, if agents have to bear direct costs to diversify their portfolios, they might diversify 
too little, since they do not realize the full benefit of diversification. In these cases, subsidies that encourage diversification may improve welfare.

To assess the applicability of our model to real-world episodes of contagion, we need to check whether the crucial assumptions of the model regarding the international investors are broadly consistent with the characteristics of real-world investors. An analysis of the model reveals two critical requirements: First, that investors hold considerable proportions of their wealth in each of the two countries, and second, that their aversion to risk significantly increases following a decrease in wealth. A priori, these two assumptions may seem contradictory since risk-averse investors would be expected to diversify their portfolios across many countries rather than hold considerable amounts of wealth in any one country. In the penultimate section of the paper, we explain why the two requirements are not necessarily conflicting in our framework. We then focus on two important types of international investors - international banks and international investment funds-and explain why they may fit our model. Finally, we review empirical evidence from the literature according to which banks and investment funds played an important role in recent episodes of contagion.

A few recent theoretical papers have studied contagion. Masson [27] discusses the possibility that self-fulfilling crises will be contagious but does not present a mechanism through which a crisis in one country might induce a change in beliefs in another. Dasgupta [11] uses Carlsson and van-Damme's technique in order to provide such a mechanism. However, the mechanism in his paper differs from ours in that it relies on the existence of capital links between financial institutions. Allen and Gale [1] and Lagunoff and Schreft [26] present similar models in which the capital links between banks or projects induce a chain of crises. Some authors analyze contagion as a transmission of information. In these models, a crisis in one market reveals some information about the fundamentals in the other and thus may induce a crisis in the other market as well. Examples include King and Wadhwani [22], Calvo [3] and Chen [7]. Calvo and Mendoza [4] suggest that the high cost of gathering information on each and every country may induce rational contagion.

A few papers show that contagion can be the result of optimal portfolio allocations made by investors (see [23,25,37]). The basic difference between these papers and ours lies in the nature of the crises they describe. In these papers, a crisis has no real consequences but rather leads to changes in asset prices only. In contrast, the self-fulfilling crises studied in our paper are by their nature real crises that lead to changes in production and output. Moreover, due to our interest in such crises, the techniques we use to solve the model and find a contagion result are very different from those used in the other papers. Finally, since the other models deal only with prices, they cannot be used to discuss the welfare questions that we analyze.

The remainder of the paper is organized as follows: Section 2 presents the basic model. In Section 3, we study the equilibrium behavior of agents in the two countries. In Section 4, we demonstrate the contagion of crises from country 1 to country 2, and the resulting positive correlation between the returns in the two countries. Section 5 extends the model in order to analyze the effect of different 
degrees of diversification on welfare. In Section 6, we discuss the applicability of the model to real-world phenomena. Section 7 concludes. Proofs are relegated to the Appendix.

\section{The model}

There is a continuum $[0,1]$ of identical agents. Their utility from consumption, $u(c)$, is twice continuously differentiable, increasing, and satisfies decreasing absolute risk aversion, that is, $-u^{\prime \prime}(c) / u^{\prime}(c)$ is decreasing. Each agent holds an investment of 1 in each of two countries (1 and 2$).^{8}$

An agent can choose when to withdraw each of her two investments. The (gross) return on investment in country $i$ is 1 if withdrawn prematurely or $R\left(\theta_{i}, n_{i}\right)$ if withdrawn at maturity. Long-term return $R$ in country $i$ is increasing in the fundamentals $\theta_{i}$ of that country and decreasing in the proportion $n_{i}$ of agents who prematurely withdraw their investments in that country. The fact that the return is decreasing in $n_{i}$ may represent increasing returns on aggregate investment in country $i$ or liquidity constraints. ${ }^{9}$

An agent decides when to withdraw her investment in country $i$ after receiving information about the fundamentals in that country. The fundamentals $\theta_{1}$ and $\theta_{2}$ are independent and drawn from a uniform distribution on $[0,1]$. We assume that the fundamentals are not publicly reported. Instead, each agent $j$ obtains a noisy signal $\theta_{i}^{j}$ on the fundamentals of country $i$, where $\theta_{i}^{j}=\theta_{i}+\varepsilon_{i}^{j}$ and $\varepsilon_{i}^{j}$ are error terms which are uniformly distributed over the interval $[-\varepsilon, \varepsilon]$ and independent across agents and countries. We will focus on the case in which signals are rather precise, i.e. $\varepsilon$ is small.

Clearly, an agent's incentive to wait until her investment in country $i$ matures is higher when the country's fundamentals are good and when the number of agents who are going to withdraw early in that country is low. However, while the optimal behavior of an agent in country $i$ usually depends on her belief regarding the behavior of other agents in that country, we assume that there are small ranges of the fundamentals in which agents have dominant actions. More specifically, when the fundamentals of country $i$ are very good, an agent will prefer to keep her investment there until it matures no matter what she believes other agents will do. Similarly, when the fundamentals in country $i$ are very bad, the agent will withdraw her investment in that country prematurely even if she believes that all the other agents will maintain their investments there.

\footnotetext{
${ }^{8}$ While we assume that agents initially split their investments equally between the two countries, this would be an endogenous property if each country was, ex ante, as likely to become country 1 .

${ }^{9}$ While increasing returns to scale or liquidity constraints result in $n_{i}$ having a negative effect on the return, other factors may lead to a positive effect. For example, wages may fall when investment is reduced, thus leading to a higher return. Our assumption that the return decreases in $n_{i}$ implies that the effects of the first type are dominant. We believe this assumption is realistic for the case of emerging markets.
} 

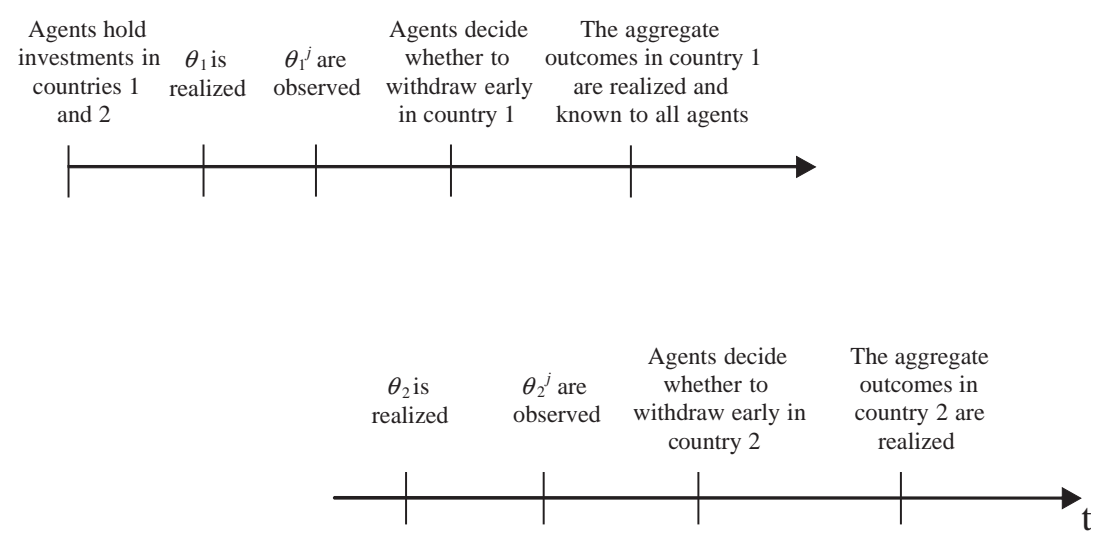

Fig. 1. The order of events.

Formally, we assume that there exist $2 \varepsilon<\underline{\theta}<\bar{\theta}<1-2 \varepsilon$ such that $R(\underline{\theta}, 0)=1$ and $R(\bar{\theta}, 1)=1$. When an agent observes a signal $\theta_{i}^{j}<\underline{\theta}-\varepsilon$, she knows that $R_{i}<1$ no matter what other agents are going to do in country $i$. Thus, she will decide to withdraw her investment in country $i$. Similarly, if an agent observes $\theta_{i}^{j}>\bar{\theta}+\varepsilon$, she will decide to keep her investment in country $i$ until it matures. Note that for most possible signals, i.e. when $\theta_{i}^{j}$ is between $\underline{\theta}+\varepsilon$ and $\bar{\theta}-\varepsilon$, the optimal behavior of an agent in country 2 will depend on her belief regarding the behavior of other agents there.

The model is sequential: activity takes place first in country 1 and then in country 2. In the first stage, the fundamentals in country 1 are realized, agents receive signals regarding the fundamentals and decide whether to withdraw their investments there prematurely or not. In the second stage, the fundamentals in country 2 are realized, agents observe signals and decide on their actions in that country. The exact realization of country 1 fundamentals, as well as the aggregate behavior in country 1 , are known to agents before they choose their actions in country $2 .{ }^{10}$ The order of events is depicted in Fig. 1.

\section{Solving the model}

We solve the model backwards. We first analyze the equilibrium behavior of agents in country 2 for each possible outcome in country 1 . We then analyze the equilibrium behavior of agents in country 1 when they take into account the effect of the outcomes in country 1 on the equilibrium in country 2 .

\footnotetext{
${ }^{10}$ In equilibrium, it is sufficient that agents receive information regarding either the fundamentals or aggregate behavior, since one can be inferred from the other.
} 


\subsection{Equilibrium in country 2}

In her decision whether to run or not in country 2, an agent should take into account all relevant available information. This includes her signal $\theta_{2}^{j}$ of country 2's fundamentals and her wealth $w_{1}^{j}$ resulting from her investment in country 1 , since these directly affect her incentive to run. Moreover, since her payoff depends on other agents' behavior and since this behavior might depend on their own wealth, the agent must also consider the distribution of wealth in the population. (The agent is also concerned about the signals observed by other agents; however, the only information she has about them is her own signal $\theta_{2}^{j}$.)

Suppose that agent $j$ believes that the proportion of other agents who will run in country 2 as a function of country 2's fundamentals, is given by $n_{2}^{j}\left(\theta_{2}\right) .{ }^{11}$ The difference between the utility she expects in the case that she keeps her investment in country 2 until it matures and the case in which she withdraws early is:

$$
\Delta_{2}\left(\theta_{2}^{j}, n_{2}^{j}(\cdot), w_{1}^{j}\right)=\frac{1}{2 \varepsilon} \int_{\theta_{2}=\theta_{2}^{j}-\varepsilon}^{\theta_{2}^{j}+\varepsilon}\left[u\left(R\left(\theta_{2}, n_{2}^{j}\left(\theta_{2}\right)\right)+w_{1}^{j}\right)-u\left(1+w_{1}^{j}\right)\right] d \theta_{2} .
$$

(Note that when agent $j$ observes signal $\theta_{2}^{j}$, her posterior belief over the fundamentals in country 2 is uniformly distributed between $\left[\theta_{2}^{j}-\varepsilon\right]$ and $\left[\theta_{2}^{j}+\varepsilon\right]$. This is because her prior belief over $\theta_{2}$ is uniformly distributed and the signal error $\varepsilon_{2}^{j}$ is uniformly distributed over $[-\varepsilon, \varepsilon]$.)

For a given distribution of wealth in the population, an agent's strategy is a function from her signal to an action-run $(r)$ or not run $(n r)$. The profile of strategies of all agents induces a function $n_{2}\left(\theta_{2}\right)$ which determines the number of agents who run given the true state of fundamentals. In equilibrium, all agents know $n_{2}\left(\theta_{2}\right)$ (i.e., $n_{2}^{j}\left(\theta_{2}\right)=n_{2}\left(\theta_{2}\right)$ for all $\left.j\right)$. Thus, in equilibrium, it must be that each agent $j$ runs if and only if $\Delta_{2}\left(\theta_{2}^{j}, n_{2}(\cdot), w_{1}^{j}\right)<0$.

The distribution of wealth consists of two mass points: the $n_{1}$ agents who ran in country 1 have wealth 1 , whereas the $1-n_{1}$ who did not have wealth $R\left(\theta_{1}, n_{1}\right) .{ }^{12}$ As a result, an agent's equilibrium strategy may depend on her group. Proposition 1 states that for any distribution of wealth (as determined by $n_{1}$ and $\theta_{1}$ ), there is a unique equilibrium in country 2 . The equilibrium is characterized by two threshold signals: each agent runs if she observes a signal below the threshold corresponding to her group, and does not if her signal is above it.

\footnotetext{
${ }^{11}$ For the ease of exposition we denote here the belief as deterministic. While this must be the case in a symmetric pure Bayesian equilibrium, a priori an agent might have a probabilistic belief (i.e., for a given $\theta_{2}, n_{2}^{j}\left(\theta_{2}\right)$ may be a random variable). In the proof of Proposition 1 (existence and uniqueness of equilibrium in country 2) we do allow arbitrary beliefs, and show that the unique equilibrium is indeed pure and symmetric. In the proof of Proposition 2 (existence of equilibrium in country 1), the equilibrium that we construct is pure and symmetric.

${ }^{12}$ It might be that $n_{1}$ equals 0 or 1 or that $R\left(\theta_{1}, n_{1}\right)=1$. In these cases, all agents have the same wealth.
} 
Proposition 1. For any $\theta_{1}$ and $n_{1} \in[0,1]$, there exists a unique equilibrium in country 2. In this equilibrium, each agent who ran in country 1 runs in country 2 if her signal $\theta_{2}^{j}$ is below $\theta_{2, r}^{*}$ and does not run if the signal is above, whereas an agent who did not run in country 1 runs in country 2 if her signal is below $\theta_{2, n r}^{*}$ and does not run above.

Remark. Although the behavior of agents is uniquely determined in Proposition 1, crises (i.e. mass withdrawals of investment) in country 2 are self-fulfilling. In the range in which agents do not have dominant actions, i.e., between $\underline{\theta}$ and $\bar{\theta}$, whenever agents run they do so only because they believe other agents are going to. The crucial point is that the fundamentals of country 2 uniquely determine agents' beliefs and these, in turn, determine their behavior.

The intuition behind the uniqueness result relies on the structure of information and on the assumption that there are regions of the fundamentals in which agents have dominant actions. The fact that agents must run at signals below $\underline{\theta}-\varepsilon$ implies that they also run at higher signals. This is because when an agent observes a signal that is slightly higher than $\underline{\theta}-\varepsilon$, she knows the signals of many other agents are below $\underline{\theta}-\varepsilon$. Therefore, due to strategic complementarities, this agent decides to run. Using this line of argument again and again, we can expand the range of signals in which we know agents will run. Similarly, we can apply the same argument starting from the upper dominance region (above $\bar{\theta}+\varepsilon$ ), and expand the range of signals in which we know agents will not run.

To complete the intuition, we need to explain why, for each of the two types of agents (those who ran in country 1 and those who did not), the two respective ranges meet. That is, we need to show that there is no middle region in which the iterative procedure does not say what the agents will do. The intuition for the case in which all agents have the same wealth is relatively simple. ${ }^{13}$ In this case, the iterative process that starts from the lower dominance region leads to a limit signal $\theta^{\infty}$, below which agents must run. The condition that determines $\theta^{\infty}$ is that an agent is indifferent there under the most optimistic belief: that while other agents always run below $\theta^{\infty}$, they never run above. Similarly, the iterative process that starts from the upper dominance region leads to a limit signal $\tilde{\theta}^{\infty}$, above which agents do not run. At this signal, an agent is indifferent under the most pessimistic belief: that while other agents never run above $\tilde{\theta}^{\infty}$, they always run below. Since the beliefs in both cases are the same, the agents cannot be indifferent both at $\theta^{\infty}$ and at $\tilde{\theta}^{\infty}$, unless the two points coincide.

Our case of two groups of agents, however, is more involved. Yet, because strategies are complementary not only within a group but also across groups (i.e., the incentive of an agent to withdraw early in country 2 increases if more agents of either group withdraw early), the uniqueness of equilibrium holds also in our case. For a

\footnotetext{
${ }^{13}$ This case has been analyzed in many papers; see, for example [28].
} 
detailed intuition for general games with strategic complementarities (with multiple player types and multiple actions), see [13]. ${ }^{14}$

While Proposition 1 allows for the two thresholds to be distinct, we now show that they must be very close if agents' signals are very accurate. Lemma 1 states that the distance between the two is of order $\varepsilon$ :

Lemma 1. $\left|\theta_{2, r}^{*}-\theta_{2, n r}^{*}\right| \leqslant 2 \varepsilon$.

The intuition behind the lemma is as follows: If the distance were larger than $2 \varepsilon$, then the support of the posterior distribution over $\theta$ for an agent who observes the higher threshold signal would be above that of an agent who observes the lower threshold signal. (This is because the noise in the signals is no more than $\varepsilon$.) Similarly, the support of her distribution over the number of agents who run would be below it. Thus, independent of her wealth, she would have a higher incentive to maintain her investment, contradicting the fact that both should be indifferent.

\subsection{Equilibrium in country 1}

When agent $j$ chooses her action in country 1 , the only information she has is her signal $\theta_{1}^{j}$ regarding the fundamentals of that country. Her decision also depends on her belief $n_{1}^{j}\left(\theta_{1}\right)$ regarding the number of agents who are going to withdraw early in country 1 as a function of the fundamentals in that country. Another relevant factor is the wealth, $w_{2}^{j}$, that she expects to obtain from her investment in country 2 . This wealth will depend on country- 2 fundamentals, $\theta_{2}$, and on the signal, $\theta_{2}^{j}$, that the agent will observe in country 2. More formally, given the equilibrium behavior in country 2 , in case the agent runs (does not run) in country 1 , the wealth she will obtain in country 2 is $w_{2, r}\left(w_{2, n r}\right)$. These are given by

$$
\begin{aligned}
& w_{2, r}\left(\theta_{1}, n_{1}^{j}\left(\theta_{1}\right) ; \theta_{2}, \theta_{2}^{j}\right)= \begin{cases}1, & \theta_{2}^{j}<\theta_{2, r}^{*}\left(\theta_{1}, n_{1}^{j}\left(\theta_{1}\right)\right), \\
R\left(\theta_{2}, n_{2}\left(\theta_{2}\right)\right), & \theta_{2}^{j} \geqslant \theta_{2, r}^{*}\left(\theta_{1}, n_{1}^{j}\left(\theta_{1}\right)\right),\end{cases} \\
& w_{2, n r}\left(\theta_{1}, n_{1}^{j}\left(\theta_{1}\right) ; \theta_{2}, \theta_{2}^{j}\right)= \begin{cases}1, & \theta_{2}^{j}<\theta_{2, n r}^{*}\left(\theta_{1}, n_{1}^{j}\left(\theta_{1}\right)\right), \\
R\left(\theta_{2}, n_{2}\left(\theta_{2}\right)\right), & \theta_{2}^{j} \geqslant \theta_{2, n r}^{*}\left(\theta_{1}, n_{1}^{j}\left(\theta_{1}\right)\right) .\end{cases}
\end{aligned}
$$

Note that since, by Lemma 1 , the thresholds $\theta_{2, r}^{*}$ and $\theta_{2, n r}^{*}$ are very close to each other, $w_{2, r}$ and $w_{2, n r}$ are the same for most of the realizations of $\theta_{2}^{j}$.

Now, agent $j$ will withdraw early in country 1 if and only if $\Delta_{1}\left(\theta_{1}^{j}, n_{1}^{j}\left(\theta_{1}\right)\right)<0$, where $\Delta_{1}$ denotes the difference between the utility that the agent expects to achieve

\footnotetext{
${ }^{14}$ Another application in which a unique equilibrium is obtained with two types of agents can be found in [14].
} 
in the case that she keeps her investment in country 1 until it matures and the utility she expects to achieve in the case that she withdraws early. It is given by

$$
\begin{aligned}
& \frac{1}{2 \varepsilon} \int_{\theta_{1}=\theta_{1}^{j}-\varepsilon}^{\theta_{1}^{j}+\varepsilon} \int_{\theta_{2}=0}^{1} \frac{1}{2 \varepsilon} \int_{\theta_{2}^{j}=\theta_{2}-\varepsilon}^{\theta_{2}+\varepsilon} \\
& {\left[\begin{array}{c}
u\left(R\left(\theta_{1}, n_{1}^{j}\left(\theta_{1}\right)\right)+w_{2, n r}\left(\theta_{1}, n_{1}^{j}\left(\theta_{1}\right) ; \theta_{2}, \theta_{2}^{j}\right)\right) \\
-u\left(1+w_{2, r}\left(\theta_{1}, n_{1}^{j}\left(\theta_{1}\right) ; \theta_{2}, \theta_{2}^{j}\right)\right)
\end{array}\right] d \theta_{2}^{j} d \theta_{2} d \theta_{1} .}
\end{aligned}
$$

The analysis of equilibrium behavior in country 1 is more involved than that of country 2. The reason is that apart from the effect of $\theta_{1}$ and $n_{1}$ on $R\left(\theta_{1}, n_{1}\right)$, which directly affects the desirability of early withdrawal, there is also an indirect effect: $\theta_{1}$ and $n_{1}$ determine $w_{2, r}$ and $w_{2, n r}$, which in turn affect $\Delta_{1}$. As a result, we do not know whether $\Delta_{1}$ is monotonic in $\theta_{1}$ and $n_{1}$, and thus we are unable to show that the equilibrium in country 1 is unique. We can, however, show the existence of a threshold equilibrium, i.e., an equilibrium in which all agents withdraw early when they observe a signal below some common threshold $\theta_{1}^{*}$ and wait if they observe a signal above. The proof of existence of this equilibrium is obtained due to the fact that when $\varepsilon$ is sufficiently small, $w_{2, r}$ and $w_{2, n}$ are the same for most realizations of $\theta_{2}$ (Lemma 1).

Proposition 2. For sufficiently small $\varepsilon$, there exists a threshold equilibrium in country 1.

\section{Contagion of crises and endogenous correlation between returns}

\subsection{The effect of wealth from country 1 operations on the equilibrium in country 2}

The unique thresholds $\theta_{2, r}^{*}$ and $\theta_{2, n r}^{*}$, below which agents run in country 2 , depend on the distribution of wealth from country- 1 operations, as determined by $n_{1}$ and $\theta_{1}$. Our main result shows that if the population is wealthier (in distribution), crises in country 2 become less likely:

Theorem 1. If the distribution of agents' wealth corresponding to $n_{1}^{\prime}$ and $\theta_{1}^{\prime}$ first-order stochastically dominates that corresponding to $n_{1}$ and $\theta_{1}$, then $\theta_{2, r}^{*}\left(\theta_{1}^{\prime}, n_{1}^{\prime}\right)<\theta_{2, r}^{*}\left(\theta_{1}, n_{1}\right)$ and $\theta_{2, n r}^{*}\left(\theta_{1}^{\prime}, n_{1}^{\prime}\right)<\theta_{2, n r}^{*}\left(\theta_{1}, n_{1}\right)$.

The intuition behind this result is as follows: In country 2, each agent has to choose between two actions: The first action is a safe one in which the agent withdraws her investment in country 2 early and receives a certain return of 1 . The second action is a risky one in which the agent keeps her investment in country 2 until it matures and receives an uncertain return at that time. Since risk aversion decreases with wealth, those agents with increased wealth from their country 1 investments will be more willing to bear risks. As a result, these agents will 
coordinate on maintaining their investments in country 2 over a wider range of realizations of the fundamentals in that country. Consequently, and because of the strategic complementarities, those agents whose wealth has not changed will also have a stronger incentive to maintain their investment. As a result, the thresholds below which all agents run in country 2 will be lower.

It is important to note that the risk involved in not withdrawing early in country 2 is not a result of the uncertainty about the level of the fundamentals in that country. This is because, when $\varepsilon$ is small, agents have relatively accurate information about the level of these fundamentals, which makes this uncertainty negligible. Rather, agents face strategic risk: when they choose to maintain their investments, their return depends on the unknown behavior of other agents. ${ }^{15}$ In other words, agents in our model are averse to being in situations where their payoff depends on the behavior of others. This aversion, however, decreases with their level of wealth.

The implications of Theorem 1 go beyond our model. Consider, for example, a hypothetical case in which all agents have an identical level of wealth which is given exogenously. According to the theorem, the likelihood of a run in country 2 decreases with that level of wealth. This case can be interpreted as a situation in which country 1 is a developed country, which is already beyond the stage at which investments are fragile, so that their return is no longer sensitive to the number of investors. (Thus, the return in country 1 would be $R\left(\theta_{1}\right)$.) Country 2 could be thought of as an emerging market, in which investments are still fragile (i.e., the return is $R\left(\theta_{2}, n_{2}\right)$ ). In such a scenario, bad news on the developed country's fundamentals might generate a crisis in the emerging economy.

Returning to our model (in which the two countries can be thought of as emerging markets), we now demonstrate the contagion of crises and the correlation between the returns in the two countries. To ease the exposition, we now focus on the limit case, in which $\varepsilon$ approaches zero. In the limit, there exists a threshold $\theta_{2}^{*}\left(\theta_{1}, n_{1}\right)$ such that all agents run in country 2 below $\theta_{2}^{*}$ and do not run above. ${ }^{16}$ Because $\theta_{2}$ is uniformly distributed over $[0,1], \theta_{2}^{*}$ also represents the probability of a crisis in country 2 .

\subsection{Contagion of crises}

Theorem 1 implies that there exists a contagion effect: the behavior of agents in country 1 affects their behavior in country 2 . For a given realization of $\theta_{1}$ above the lower dominance region, when there is a run in country 1 , the distribution of wealth is below that corresponding to the case of no run. Thus, $\theta_{2}^{*}\left(\theta_{1}, 1\right)$ is above $\theta_{2}^{*}\left(\theta_{1}, 0\right)$. This implies that a run in country 1 increases the likelihood of a run in country 2 . This is stated in the following corollary, and shown in Fig. 2.

\footnotetext{
${ }^{15}$ In fact, only agents who receive signals that are very close to the thresholds have any uncertainty about the behavior of other agents. Thus, a change in the level of wealth will have a direct effect only on the behavior of these agents. However, since the optimal behavior of agents who observe other signals depends on the behavior of these agents, the change in wealth will have an indirect effect on the behavior of other agents as well. Thus, a change in wealth will change the behavior of a large group of agents.

${ }^{16}$ The existence of such a limit threshold is guarantied by Lemma 1 above and by Lemma 2 in the appendix. Lemma 2 also characterizes the threshold $\theta_{2}^{*}\left(\theta_{1}, n_{1}\right)$.
} 


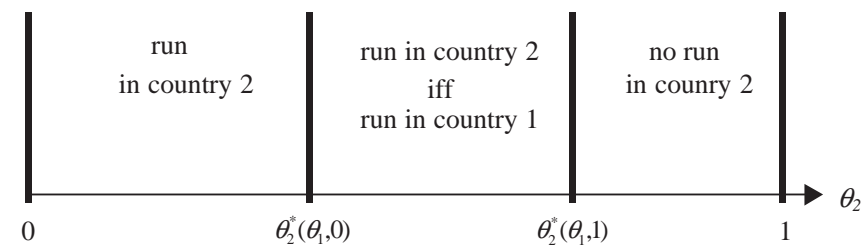

Fig. 2. Contagion of crises.

Corollary. Assume that $R\left(\theta_{1}, 0\right)>1$. There is a range of country 2 fundamentals in which: if there is a run in country $1\left(n_{1}=1\right)$, then there will also be one in country 2, and if there is no run in country $1\left(n_{1}=0\right)$, then there will not be one in country 2.

It is also interesting to study the effect of changes in $n_{1}$, when it is strictly between 0 and 1 , on the equilibrium behavior in country 2 . To this end, recall that $R\left(\theta_{1}, n_{1}\right)$ is decreasing in $n_{1}$, exceeds 1 when $n_{1}$ is small and falls below 1 when $n_{1}$ is close to 1 . In the range where $R\left(\theta_{1}, n_{1}\right)$ is greater than 1 , an increase in $n_{1}$ has a negative effect on the distribution of agents' wealth. The reason is that the number of agents who run and receive 1 becomes larger and the number of agents who wait and receive $R\left(\theta_{1}, n_{1}\right)$ becomes smaller. Moreover, the wealth of agents in the second group is reduced since $R\left(\theta_{1}, n_{1}\right)$ is decreasing in $n_{1}$. Thus, by Theorem 1 , when more agents run in country 1 there is a higher likelihood of a run in country 2.

In the range where $R\left(\theta_{1}, n_{1}\right)$ is below 1 , however, the effect of $n_{1}$ on $\theta_{2}^{*}$ becomes ambiguous. When an additional agent decides to run, her wealth is increased from $R\left(\theta_{1}, n_{1}\right)$ to 1 . On the other hand, the wealth of those agents who do not run is decreased. Nonetheless, we do know that if $n_{1}$ is increased to 1 , agents' wealth is increased since in that case all agents receive a return of 1 . These results are summarized in Fig. 3.

\subsection{Correlation}

To analyze the correlation between the returns in the two countries, we now focus on a given threshold equilibrium in country 1, which is characterized by the threshold signal $\theta_{1}^{*}$. With a small amount of noise in the signals, the behavior of agents in country 1 can be approximately described as follows: All agents run in country 1 when the fundamentals there are below $\theta_{1}^{*}$, whereas none of them does so when the fundamentals in country 1 are above $\theta_{1}^{*}$. In the first case, all agents possess wealth $w_{1}=1$, while in the second each has wealth $R\left(\theta_{1}, 0\right)>1$. By the results of Theorem 1, in the first case agents will run in country 2 when the fundamentals are below the threshold $\theta_{2}^{*}\left(w_{1}=1\right)$, which is higher than the threshold $\theta_{2}^{*}\left(w_{1}=R\left(\theta_{1}, 0\right)\right)$ corresponding to the second case. This is illustrated in Fig. 4 (note that since $\theta_{2}$ is uniformly distributed between 0 and $1, \theta_{2}^{*}$ is simply the probability of a run in country 2). 


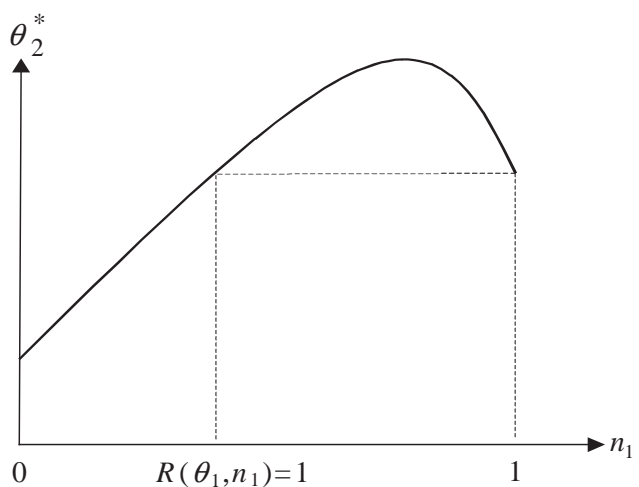

Fig. 3. The effect of $n_{1}$ on $\theta_{2}^{*}$ for a given realization of $\theta_{1}$ at which $R\left(\theta_{1}, 0\right)>1$.

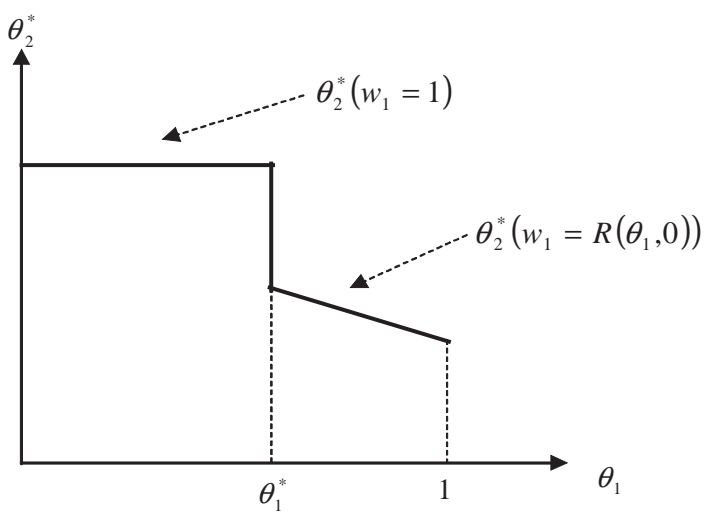

Fig. 4. The probability of a run in country 2 as a function of the fundamentals in country 1 .

As shown in Fig. 4, when the fundamentals in country 1 are below $\theta_{1}^{*}$, the probability of a crisis in country 2 is fixed at $\theta_{2}^{*}\left(w_{1}=1\right)$. When the fundamentals in country 1 reach the level of $\theta_{1}^{*}$ there is a discontinuous decline in the probability of a run in country 2. This occurs because at this level of fundamentals, agents switch from running to waiting in country 1 and therefore enjoy a discontinuous increase in the wealth they obtain from their investments in that country. Finally, when the fundamentals in country 1 increase beyond $\theta_{1}^{*}$, the probability of a run in country 2 gradually decreases. This occurs because at this level of fundamentals, agents do not run in country 1 and their wealth $w_{1}=R\left(\theta_{1}, 0\right)$ increases gradually with the level of fundamentals there.

Thus, an endogenous spillover effect exists, whereby the level of fundamentals in country 1 affects the probability of crisis in country 2. This generates a positive correlation between the returns on investments in the two countries. Importantly, this correlation occurs in spite of the fact that the fundamentals in the two countries 


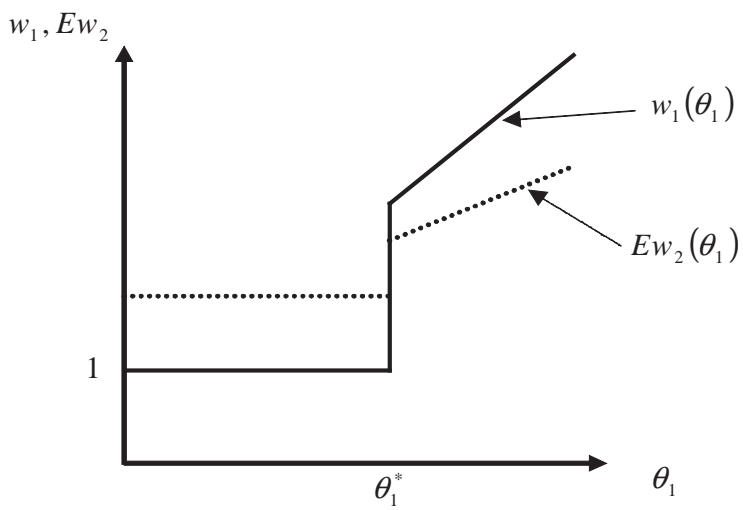

Fig. 5. The returns on the two investments as functions of the fundamentals in country 1.

are completely independent of each other. It emerges only from the wealth effect, which induces agents to coordinate on the better equilibrium more often when they obtain higher returns on their investments in country 1 .

Fig. 5 demonstrates the positive correlation between the returns on investments in the two countries (in the threshold equilibrium previously described). The return on investment in country 1 is $w_{1}\left(\theta_{1}\right)$. It equals 1 below $\theta_{1}^{*}$ and $R\left(\theta_{1}, 0\right)$ above. The expected return in country 2 is $E w_{2}\left(\theta_{1}\right)=\theta_{2}^{*}\left(\theta_{1}, n_{1}\left(\theta_{1}\right)\right)+\int_{\theta_{2}=\theta_{2}^{*}\left(\theta_{1}, n_{1}\left(\theta_{1}\right)\right)}^{1} R\left(\theta_{2}, 0\right) d \theta_{2}$. $\left(n_{1}\left(\theta_{1}\right)\right.$ equals 1 below $\theta_{1}^{*}$ and 0 above.) A positive correlation exists because both $w_{1}\left(\theta_{1}\right)$ and $E w_{2}\left(\theta_{1}\right)$ are increasing in $\theta_{1}$.

\section{Diversification and welfare}

In the previous sections, we saw that when agents diversify their investment portfolios, they affect the real economy, i.e., the probabilities of crises. When they choose the initial allocation of their portfolios, agents ignore this externality and consider only the fact that diversification reduces the variance of their portfolios' returns. Therefore, when the two assets are symmetric, agents choose to diversify their portfolios fully between the two countries. A natural question to ask is whether government intervention that puts restrictions on diversification-such as capital controls that limit an agent's right to invest in another country-can be welfare improving.

In this section, we study an extension of the model, in which agents are not allowed to fully diversify their portfolios, and analyze the overall effect of the degree of diversification on agents' welfare. We will highlight the main channels through which diversification affects welfare in this model and construct an example in which full diversification is not optimal. Since the extended model is more complicated, we lose part of the analytical tractability in this section and therefore demonstrate our conclusions using computational simulations. 


\subsection{The new framework}

There is a continuum [0,1] of agents, half of which represents residents of country $A$ and half of which represents residents of country B. Each agent holds an initial endowment of 2, which is split between the two countries as follows: The agent holds an investment of $(1+\beta)$ in her home country and $(1-\beta)$ in the foreign country. The parameter $\beta$ captures the degree of diversification and is identical for all agents. Note that the case of $\beta=0$ is equivalent to the model studied earlier with full diversification; $\beta=1$ is the case of no diversification; and $0<\beta<1$ corresponds to partial diversification. To simplify the welfare analysis, we look at a framework in which agents from the two countries are ex ante identical. We do this by assuming that ex ante it is not known which country will become country 1, i.e., the first country in which investment decisions are made and that country A and country B have the same likelihood of becoming country $1 .^{17}$

The introduction of the parameter $\beta$ into the model affects the analysis considerably. In country 2 , agents now belong to four different groups (as opposed to two groups in the original model): Country-1 residents who ran in country 1 , country-1 residents who did not run in country 1 , country-2 residents who ran in country 1 , and country- 2 residents who did not run in country 1 . Thus, the analysis of the equilibrium outcomes in country 2 is now much more involved. Following the same reasoning as in Section 3, we can show that there are four different threshold signals in country 2 , each characterizing the behavior of agents from a different group. Moreover, as the signals' noise $\varepsilon$ approaches 0 , the four threshold signals converge to one value, which is a function of the outcome in country 1 and of $\beta$. Thus, we denote the limit threshold signal below which agents run in country 2 as $\theta_{2}^{*}\left(\theta_{1}, n_{1}, \beta\right)$. Similarly, we can show the existence of a threshold signal in country 1 which we denote by $\theta_{1}^{*}(\beta)$.

Using this notation, the expected welfare of country-1 agents can be written as:

$$
\begin{aligned}
E W_{1}(\beta)= & \int_{\theta_{1}=0}^{\theta_{1}^{*}(\beta)}\left[\begin{array}{c}
\int_{\theta_{2}=0}^{\theta_{2}^{*}\left(\theta_{1}, 1, \beta\right)} u((1+\beta) \cdot 1+(1-\beta) \cdot 1) d \theta_{2} \\
+\int_{\theta_{2}=\theta_{2}^{*}\left(\theta_{1}, 1, \beta\right)}^{1} u\left((1+\beta) \cdot 1+(1-\beta) \cdot R\left(\theta_{2}, 0\right)\right) d \theta_{2}
\end{array}\right] d \theta_{1} \\
& +\int_{\theta_{1}=\theta_{1}^{*}(\beta)}^{1}\left[\begin{array}{c}
\int_{\theta_{2}=0}^{\theta_{2}^{*}\left(\theta_{1}, 0, \beta\right)} u\left((1+\beta) \cdot R\left(\theta_{1}, 0\right)+(1-\beta) \cdot 1\right) d \theta_{2} \\
+\int_{\theta_{2}=\theta_{2}^{*}\left(\theta_{1}, 0, \beta\right)}^{1} u\left((1+\beta) \cdot R\left(\theta_{1}, 0\right)+(1-\beta) \cdot R\left(\theta_{2}, 0\right)\right) d \theta_{2}
\end{array}\right] d \theta_{1} .
\end{aligned}
$$

Here, in country 1 , agents obtain a return of $R\left(\theta_{1}, 0\right)$ when the realization of $\theta_{1}$ is above $\theta_{1}^{*}$ and a return of 1 when it is below. Similarly, in country 2, agents obtain a return of $R\left(\theta_{2}, 0\right)$ when the realization of $\theta_{2}$ is above $\theta_{2}^{*}$ and a return of 1 below. Since they are country-1 agents, the weight of country-1 investments in their portfolio is $(1+\beta)$ and the weight of country- 2 investments in their portfolio is $(1-\beta)$. The level of $\beta$ also affects the threshold signals $\theta_{1}^{*}$ and $\theta_{2}^{*}$.

\footnotetext{
${ }^{17}$ Under these assumptions, it is clear that if agents are legally constrained to invest no more than $1-\beta$ in the foreign country, they will choose the corner solution of investing exactly $1-\beta$ there.
} 
The expected welfare of country-2 agents can be computed in a similar way (the only difference is that the agent puts weight $(1-\beta)$ on the return in country 1 and weight $(1+\beta)$ on country 2$)$ :

$$
\begin{aligned}
E W_{2}(\beta)= & \int_{\theta_{1}=0}^{\theta_{1}^{*}(\beta)}\left[\begin{array}{c}
\int_{\theta_{2}=0}^{\theta_{2}^{*}\left(\theta_{1}, 1, \beta\right)} u((1-\beta) \cdot 1+(1+\beta) \cdot 1) d \theta_{2} \\
+\int_{\theta_{2}=\theta_{2}^{*}\left(\theta_{1}, 1, \beta\right)}^{1} u\left((1-\beta) \cdot 1+(1+\beta) \cdot R\left(\theta_{2}, 0\right)\right) d \theta_{2}
\end{array}\right] d \theta_{1} \\
& +\int_{\theta_{1}=\theta_{1}^{*}(\beta)}^{1}\left[\begin{array}{c}
\int_{\theta_{2}=0}^{\theta_{2}^{*}\left(\theta_{1}, 0, \beta\right)} u\left((1-\beta) \cdot R\left(\theta_{1}, 0\right)+(1+\beta) \cdot 1\right) d \theta_{2} \\
+\int_{\theta_{2}=\theta_{2}^{*}\left(\theta_{1}, 0, \beta\right)}^{1} u\left((1-\beta) \cdot R\left(\theta_{1}, 0\right)+(1+\beta) \cdot R\left(\theta_{2}, 0\right)\right) d \theta_{2}
\end{array}\right] d \theta_{1} .
\end{aligned}
$$

Finally, the ex ante expected welfare of all agents is given by

$$
E W(\beta)=\frac{1}{2} E W_{1}(\beta)+\frac{1}{2} E W_{2}(\beta)
$$

\subsection{The effect of diversification on welfare: two channels}

There are two channels through which the level of diversification, $\beta$, affects the agents' ex ante expected welfare. The first is the direct channel: given two assets with exogenous distributions of returns ("shares" of country 1 and of country 2), a change in the weights of the assets in agents' portfolios affects their expected welfare. The second channel is indirect: the level of diversification affects agents' behavior and thus affects the thresholds $\theta_{1}^{*}$ and $\theta_{2}^{*}$. As a result, the level of diversification affects the distributions of the returns of the two assets and thereby indirectly affects agents' welfare. This indirect channel is the novel feature of our model. As opposed to cases in which only the direct channel exists and full diversification is always optimal, we will see that in our model partial diversification may be preferable due to the indirect channel.

\subsubsection{The direct channel}

The direct effect of $\beta$ on agents' ex ante expected welfare can be explained using standard risk sharing arguments. Since the returns in the two countries are never fully correlated and since agents are risk averse, full diversification is optimal since it minimizes the overall variance of the portfolio's return (recall that the two assets are symmetric ex ante). Thus, if only the direct effect existed, the optimal level of $\beta$ would be 0 .

\subsubsection{The indirect channel}

The novel feature of our model is the endogenous effect of $\beta$ on $\theta_{1}^{*}$ and $\theta_{2}^{*}$. Here, we can identify two effects.

Diversification and correlation: As we showed in Section 3 for the case of full diversification $(\beta=0)$, following a crisis in country 1 , agents tend to run more often in country 2 . This generates some positive correlation between the returns 


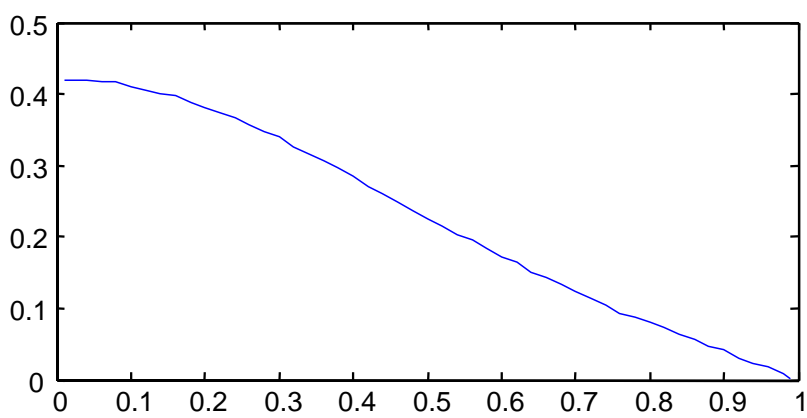

Fig. 6. Correlation between the returns as a function of $\beta$.

on the investments in the two countries. This effect of diversification also exists for every other value of $0<\beta<1$ : as long as some agents who invest in country 2 hold a portion of their investment in country 1 , their wealth will be affected by the outcome in country 1 , and this will have an effect on their decisions in country 2. Obviously, the correlation will be very small when diversification is low ( $\beta$ close to 1). Fig. 6 demonstrates the monotone effect of diversification on the correlation between the returns in the two countries. (In this example, the utility function is $u(c)=(c+0.01)^{1-7} /(1-7)$ and the return function is $R(\theta, n)=2 \theta-5 n+4) .^{18}$

The effect of diversification on correlation can be interpreted as a social cost of diversification. When agents diversify, they generate some positive correlation between the returns in the two countries and thus reduce the benefits from diversification.

Diversification and the tendency to run: If an agent holds a large portion of her portfolio in one country, a decision not to run results in a large risk to her overall wealth. Thus, she will have a stronger incentive to run in this country. When we change the level of diversification, we change the amount of money that agents hold in each country and thereby the probability of a crisis in each country. This effect of diversification does not depend on any correlation between the two countries and thus, for clarity, can be demonstrated in a model without contagion or wealth effects, i.e., with agents who have constant absolute risk aversion (note that in such a model $\theta_{2}^{*}$ always equals $\theta_{1}^{*}$ ).

An example is illustrated in Fig. 7 (the utility function in this example is $u(c)=$ $-e^{-4 c}$; the return function is the same as in the previous simulation). To understand this example, we start by comparing the probability of a crisis in the case of $\beta=1$ with the probability in the case of $\beta=0$. When $\beta=1$, the investors in each country are its residents: each one holds 2 units of investment there. When $\beta=0$, the group

\footnotetext{
${ }^{18}$ The addition of the constant 0.01 to $c$ in the utility function is made in order to avoid having $u$ equal to $-\infty$ when $c$ is 0 .
} 


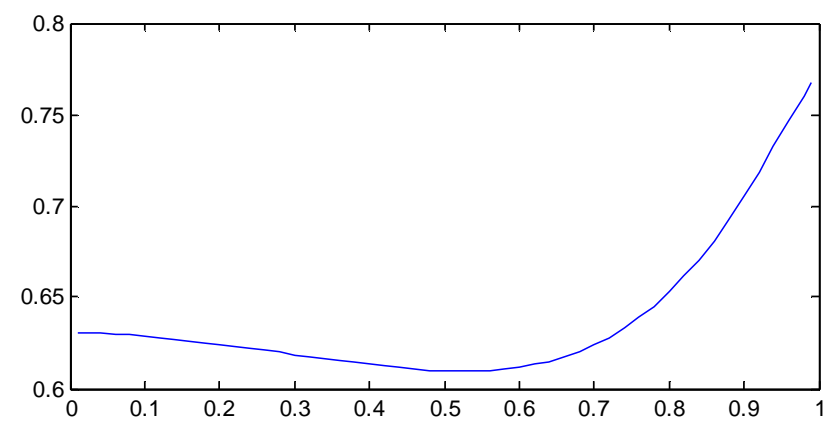

Fig. 7. The thresholds $\theta_{1}^{*}=\theta_{2}^{*}$ as a function of $\beta$ in the CARA case.

of investors in each country comprises of the residents of both countries, and each one of them holds an investment of 1 . Thus, in the latter case agents are more willing to take risks and run less often. As a result, when we move from no diversification to full diversification, agents benefit not only from risk sharing but also from lower probabilities of financial crises.

This effect of diversification on the probability of crises is, however, not necessarily monotone, as we can see in the above example. When we increase $\beta$ slightly above 0 , there are two opposite effects on the probability of a crisis in each country. On the one hand, one group of agents holds a smaller amount of money in the country and tends to run less, but on the other hand, the other group holds a larger amount in this country, and tends to run more. Thus, such a model will sometimes generate fewer crises under partial diversification than under full diversification.

\subsection{The overall effect of diversification on welfare}

To sum up, diversification affects agents' expected welfare in three ways: The direct channel, in which the stochastic returns in the two countries are taken as given, implies that welfare is monotonically increasing in the degree of diversification (i.e., monotonically decreasing in $\beta$ ). The first indirect channel has the opposite effect: when the degree of diversification is higher, the correlation between the returns in the two countries is higher and therefore the benefits from risk sharing are smaller. This implies that welfare increases monotonically in $\beta$. The second indirect channel can have a non-monotonic effect: the tendency to run can either increase or decrease with the level of diversification and thus the effect on the thresholds $\theta_{1}^{*}$ and $\theta_{2}^{*}$ can go in either direction (although full diversification always leads to less runs compared to no diversification at all). Overall, the effect of diversification on expected welfare is a priori ambiguous. This is in contrast to a model in which diversification has only a direct effect on expected welfare and full diversification is always optimal.

The complexity of our model with partial diversification does not enable us to derive analytical results as to when diversification enhances welfare and when it 


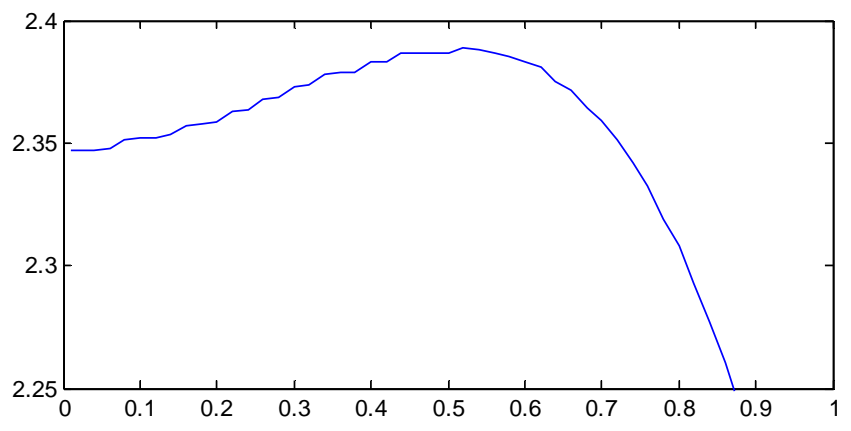

Fig. 8. Average welfare as a function of $\beta$.

reduces it. Fig. 8 provides an example in which full diversification is not optimal and a higher level of ex ante welfare can be achieved with partial diversification. (In this example, we employ again the CRRA utility function $u(c)=(c+0.01)^{1-7} /(1-7)$. The return function is the same. Expected welfare is normalized to the level of safe consumption that yields it).

To sum up, in this section we drew attention to the indirect channel through which diversification affects welfare. This additional channel can either decrease the overall benefit from diversification (and even make it negative) or increase it (as is always the case, for example, when we jump from no diversification to full diversification). Since agents ignore the indirect channel through which diversification affects welfare, government intervention that changes equilibrium patterns of diversification may improve welfare. In our model, since agents do not have to bear any costs to diversify their portfolios, they will always choose to fully diversify. Therefore, when full diversification is inferior to partial diversification-as in the example given above - capital controls can improve welfare. Another case in which government intervention may improve welfare occurs when the indirect channel increases the overall benefit from diversification and agents have to bear costs to diversify their portfolios. In such a case, agents do not realize the full benefit of diversification and thus choose to diversify too little. Then, subsidies that encourage diversification may improve welfare.

\section{Applicability of the model to real world phenomena}

In this paper, we have shown that financial crises can be transmitted from one country to another even if there is no direct link between the two countries. Contagion occurs because the two countries share the same group of investors. In order to assess whether this channel of contagion is significant in real-world situations, we need to examine the crucial assumptions of the model regarding the international investors and assess whether they are broadly consistent with the characteristics of investors in the real world. 
An analysis of the model shows that our results will have relevance in real world situations if there is a group of investors, who hold a significant proportion of both countries' assets, and have two characteristics: One, they hold a significant portion of their overall wealth in these countries (so that a crisis in country 1 has a significant wealth effect). Two, they are risk averse, and their absolute risk aversion coefficient increases considerably following a decrease in wealth (so that a change in wealth affects their incentive to run in country 2).

A priori, these two assumptions may seem to be contradictory: if investors are sufficiently risk averse to generate a considerable contagion effect, they will diversify their investments across many countries rather than concentrate them in only a few. In the remainder of this section we explain how this apparent conflict can be reconciled. We then focus on two important types of international investorsinternational banks and international investment funds-and explain why the characteristics of these investors fit our assumptions. Finally, we review evidence from a number of empirical studies, according to which banks and investment funds have indeed concentrated their portfolios in a few emerging markets and have played an important role in causing recent episodes of contagion.

\subsection{Reconciling risk aversion with concentrated portfolios}

Risk-averse investors may hold concentrated portfolios because of informational or operational advantages. This is particularly true for investments in emerging markets, to which our model can be best applied. In these countries, transparency is often poor, and many assets are not even publicly traded. Therefore, an investor in an emerging market will have to expend resources on collecting information and identifying profitable investments. This, however, will be worthwhile only if the investor holds significant claims there. Consequently, in equilibrium we may find a few investors who choose to specialize in a small number of emerging markets and trade off the benefits of diversification for higher expected returns. These investors are likely to be those who have an initial informational or operational advantage, perhaps due to geographical proximity. For example, as we discuss below, some Japanese banks find it efficient to hold significant portions of their portfolios in a few neighboring South East Asian countries, rather than diversifying across all the countries in the world. ${ }^{19}$

When they choose the allocation of their portfolios, investors will weigh the higher returns from concentration against the increased variance that results. Thus, they will choose a concentrated portfolio if the advantages of concentration are very large or if their aversion to risk at the stage of choosing the portfolio is not overly high. In the latter case, one might suspect that the contagion effect described in the model would not be very strong; however, this is not necessarily the case. In our framework, agents may ex ante (i.e. when they allocate their portfolios) expect low risks and have little desire to diversify their portfolios across many countries, while ex post (i.e.

\footnotetext{
${ }^{19}$ The role of asymmetric information in international capital flows was studied in the literature as a possible explanation for portfolio concentration and home bias (see [16]).
} 
when they decide whether to run or not) they may expect greater risks, and this may generate a significant contagion effect. There are two possible explanations for this distinction:

First, if the ex ante probability of a financial crisis in country 1 is small, the risk associated with the severe losses from a crisis will not be a major determinant in the portfolio allocation stage. However, a (rare) crisis in country 1 will reduce the expected overall wealth of agents and considerably affect their behavior in country 2.

The second explanation is somewhat more subtle. The return an agent obtains in each country can fall into three categories: (1) If $\theta$ falls below $\theta^{*}-\varepsilon$, there is a run and the agent gets 1 . (2) If $\theta$ falls above $\theta^{*}+\varepsilon$, there is no run and the agent gets $R>1$. (3) If $\theta$ falls between $\theta^{*}-\varepsilon$ and $\theta^{*}+\varepsilon$, there is a partial run. In this case, the agent might receive a return below 1 if she does not run and many other agents do. Ex ante, this last event is very rare and has probability of order $\varepsilon$. Therefore, at the portfolio allocation stage the agent knows almost for certain that she will obtain a return of at least 1 in each country. At these levels of wealth the absolute risk aversion could be low and thus the incentive to diversify could be small. However, as we showed in Section 3, the possibility that the return in country 2 will be lower than 1 governs the decision whether to run in this country or not and thus, at this stage, the absolute risk aversion might be high. This may lead to a significant contagion effect.

\subsection{International banks and investment funds}

There exists extensive evidence that a number of international banks and investment funds held significant amounts of their wealth in a small number of emerging markets on the eve of recent financial crises (see below). For these two types of investors to fit our model, we need to explain why it is reasonable to assume they are risk averse with a decreasing absolute risk aversion coefficient.

A bank may exhibit decreasing absolute risk aversion due to regulations that impose capital adequacy requirements. ${ }^{20}$ Because of such regulations, if the value of the bank's assets falls below some threshold, the bank is forced to reduce the size of its lending portfolio or raise more capital. This effectively punishes the bank and can make the bank more averse to further significant losses. To illustrate, consider the following simplified model: A bank is required to maintain a level of capital above $x$ at all times. If the value of its assets falls below $x$, the bank bears an additional cost of $k$ dollars for each lost dollar of capital. As a result, the bank's preferences over risky prospects may be represented by a function of the form:

$$
u(c)= \begin{cases}c-x & \text { if } c \geqslant x \\ (1+k)(c-x) & \text { if } c \leqslant x\end{cases}
$$

\footnotetext{
${ }^{20}$ Such requirements can be based on the Value at Risk of the bank's assets or on other measures. An extensive review of such regulations can be found in [18].
} 
where $k>0$. It is easy to see that such a "utility function" exhibits decreasing absolute risk aversion for initial wealth levels above $x .^{21}$

Investment funds may exhibit risk aversion for a similar reason. Funds are often highly leveraged and hold their investments as collateral against their liabilities. When the overall value of their investments falls below a certain threshold, they have to meet a margin call, and liquidate assets. Effectively, funds are punished when the overall value of their investments falls below a certain threshold. This leads to a utility function that is similar to the one described above. ${ }^{22}$

Investment funds may also exhibit risk aversion due to an agency problem between shareholders and managers. Investment funds are often motivated to specialize in certain segments of the world's economy and to exploit informational advantages. Their shareholders are not concerned by this concentration since they achieve diversification by holding several investment funds and thus are effectively risk neutral. The funds' managers, however, are not diversified: they are usually compensated, either explicitly or implicitly, according to the performance of the fund, and thus their wealth depends significantly on the funds' performance. $^{23}$ Then, since they are very likely to be risk averse, their decisions whether to run in country 2 will be strongly influenced by the performance of their funds in country 1 .

\subsection{Empirical evidence}

The role of international banks in recent crises has been thoroughly studied in several empirical papers (see, for example, $[5,21,38,39]$ ). These papers show that international banks held significant amounts of their wealth in countries that experienced contagious crises. Kaminsky and Reinhart [21], for example, document that on the eve of the Asian crisis, $22.1 \%$ of Japanese banks' claims in developing countries were held in Thailand, $14.3 \%$ in Korea, and $13 \%$ in Indonesia. Following the initial negative shock in Thailand, these banks withdrew their assets in countries such as Korea and Indonesia. A similar pattern was observed on the eve of the Mexican crisis: $21.8 \%$ of US banks' claims in developing countries were held in Mexico, $13 \%$ in Brazil, and $10.6 \%$ in Argentina. Following the initial shock in Mexico, the crisis spread to Argentina, Brazil, and other countries in Latin America. Van Rijckeghem and Weder [38] report that banks incurred severe losses during the Asian and Russian crises, and support this with evidence on the actions of rating agencies, who downgraded or put on watch many banks that were exposed in crisis countries.

\footnotetext{
${ }^{21}$ This functional form can help demonstrate the reconciliation of a significant contagion effect with concentrated portfolios. Consider, for example, the simple case of $x=2$. Ex ante, banks know they will almost always have a total return of at least 2 and thus have no aversion to risk and no desire to diversify their portfolios across many countries. However, when the probability that their overall return will go below 2 becomes significant-i.e., when they decide whether to run in country 2 following a run in country 1 - they are risk averse. This can generate a significant contagion effect.

${ }^{22}$ Other papers that use similar arguments to motivate institutional risk aversion are $[10,17,40]$.

${ }^{23}$ The difference between shareholders' and managers' attitude to risk, due to different patterns of diversification, has been studied in the finance literature. Recent papers analyzed the implications for assets' returns and volatility. See, for example $[9,33]$.
} 
Apart from documenting the patterns of investments of international banks, these studies also analyze the main factors behind recent episodes of contagion. They conclude that banks which held assets in several countries, prior to their being involved in a crisis, played an important role in generating the contagion of crises across these countries. In some of these papers, the existence of a common lender was found to be a more significant source for contagion than other potential sources such as trade links or common macroeconomic shocks (see Van Rijckeghem and Weder [39]). Thus, if we interpret the investors in our model to be international banks, these papers provide empirical evidence that supports our model.

International investment funds held investments across several emerging markets on the eve of recent international crises, and withdrew money from these countries during the crises. Kaminsky et al. [19], for example, demonstrate that the Mexican, Asian, and Russian crises triggered withdrawals by mutual funds from other countries. In addition, many individual funds were not diversified across many countries, but rather specialized in investing in a small number of countries. Kaminsky et al. [19] document that the number of mutual funds specializing in a specific region increased dramatically during the 1990s and that the portfolios of mutual funds were very concentrated during that period.

Several papers provide evidence that support our hypothesis that investment funds played an important role in generating contagion. Kaminsky et al. [20], who study the behavior of mutual funds specializing in Latin American countries, find that these funds engaged in contagious trading. For example, during the Mexican crisis of 1994, following the initial shock in Mexico, these funds withdrew money from other Latin American countries, and thus contributed to the contagion in the region. Interestingly, they make a distinction between the behavior of fund shareholders and managers and show that in the Mexican crisis, the managers' decisions to pull out investments were not always preceded by withdrawals by the funds' shareholders. This supports the hypothesis that in some cases the fund managers, rather than shareholders, dictate a fund's decision whether to run or not. Kaminsky and Reinhart [21] mention some anecdotal evidence which shows that countries with negligible representations in the portfolios of mutual funds were hardly affected by regional crises (for example, Colombia and Venezuela during the Mexican crisis). Another source of evidence is provided by Rigobon [35], who analyzes a case study of a change in investment ranking for Mexico. Following the upgrade of Mexico from 'non-investment' grade to 'investment' grade, the base of investors in Mexico expanded and came to include investors who were not typical emerging-markets investors. As a result, the transmission of shocks from other emerging markets to Mexico and vice versa was expected to weaken, as would be predicted by our model. Rigobon shows that this was indeed the case.

\section{Conclusions}

We have studied the contagion of self-fulfilling financial crises. The mechanism that generates contagion in our model is based on a wealth effect. Following a crisis 
in one country, agents' wealth is reduced. They are, then, less willing to bear the strategic risk that originates in the unknown behavior of other agents in the other country. As a result, they have a higher tendency to run in the second country. This means that the occurrence of a crisis in one country increases the probability of a crisis in the other. We explained why our model is consistent with the characteristics of real-world international investors and with their behavior during recent episodes of contagion.

The paper offers some new insights into the effect of diversification. Diversification affects not only the variance of portfolio returns but also the real economy via its effect on the probabilities of crises. When evaluating the social gains from diversification, it is important to account for its effect on the real economy. This additional effect may either increase or decrease the overall benefit from diversification. We showed that in some cases, full diversification can be inferior to partial diversification. Because investors ignore the effect of diversification on the real economy and consider only the moderating effect it has on the volatility of the returns of their portfolios, there may be a role for government intervention to change the equilibrium degree of diversification.

\section{Acknowledgments}

We thank Ravi Bansal, Larry Christiano, David Frankel, Eitan Goldman, Elhanan Helpman, David Hsieh, Pete Kyle, Stephen Morris, Assaf Razin, and an anonymous referee, for helpful comments. We also thank participants in seminars at the University of Geneva, the IMF, New York University, and Tel Aviv University, and participants in the conferences: "Accounting and Finance" in Tel Aviv University, and "Coordination, Incomplete Information, and Iterated Dominance: Theory and Empirics" in Pompeu Fabra University.

\section{Appendix}

Proof of Proposition 1. The proof for the cases in which all agents ran in country 1 $\left(n_{1}=1\right)$ or none did $\left(n_{1}=0\right)$ is standard - see for example [28]. The proof for the case in which both groups are nonempty is given below. It is based on the technique of Frankel, Morris and Pauzner [13].

Let $n_{2, r}^{j}\left(\theta_{2}\right)\left(n_{2, n r}^{j}\left(\theta_{2}\right)\right)$ denote agent's $j$ 's belief regarding the number of agents who ran (did not run) in country 1 and are going to run in country 2. (We allow for the possibility that these beliefs are non-deterministic. However, abusing notation, whenever we know that $n$ is degenerate, we refer to it as a real number rather than as a random variable.) Let $\Delta_{2, r}\left(\theta_{2}^{j}, n_{2, n r}^{j}\left(\theta_{2}\right), n_{2, r}^{j}\left(\theta_{2}\right)\right) \quad\left(\Delta_{2, n r}\left(\theta_{2}^{j}, n_{2, n r}^{j}\left(\theta_{2}\right), n_{2, r}^{j}\left(\theta_{2}\right)\right)\right)$ denote the difference in expected utility between waiting in country 2 and running 
there for an agent who ran (did not run) in country 1 and received a signal $\theta_{2}^{j}$ in country 2. These functions are given by

$$
\begin{aligned}
\Delta_{2, r} & \left(\theta_{2}^{j}, n_{2, n r}^{j}\left(\theta_{2}\right), n_{2, r}^{j}\left(\theta_{2}\right)\right) \\
\quad= & \frac{1}{2 \varepsilon} \int_{\theta_{2}^{j}-\varepsilon}^{\theta_{2}^{j}+\varepsilon} E\left[u\left(1+R\left(\theta_{2},\left(n_{2, n r}^{j}\left(\theta_{2}\right)+n_{2, r}^{j}\left(\theta_{2}\right)\right)\right)\right)-u(1+1)\right] d \theta
\end{aligned}
$$

and

$$
\begin{aligned}
& \Delta_{2, n r}\left(\theta_{2}^{j}, n_{2, n r}^{j}\left(\theta_{2}\right), n_{2, r}^{j}\left(\theta_{2}\right)\right) \\
& \quad=\frac{1}{2 \varepsilon} \int_{\theta_{2}^{j}-\varepsilon}^{\theta_{2}^{j}+\varepsilon} E\left[\begin{array}{c}
u\left(R\left(\theta_{1}, n_{1}\right)+R\left(\theta_{2},\left(n_{2, n r}^{j}\left(\theta_{2}\right)+n_{2, r}^{j}\left(\theta_{2}\right)\right)\right)\right) \\
-u\left(R\left(\theta_{1}, n_{1}\right)+1\right)
\end{array}\right] d \theta .
\end{aligned}
$$

Where the expectations are taken with respect to the (one-dimensional) random variables $n_{2, r}^{j}\left(\theta_{2}\right)$ and $n_{2, n r}^{j}\left(\theta_{2}\right)$. Because $R(\theta, n)$ is decreasing in $n$, both $\Delta_{2, r}$ and $\Delta_{2, n r}$ are weakly decreasing in $n_{2, r}^{j}$ and in $n_{2, n r}^{j}$ (e.g., if $n_{2, r}^{\prime j}\left(\theta_{2}\right)$ first-order stochastically dominates $n_{2, r}^{j}\left(\theta_{2}\right)$ for all $\theta_{2}$, then $\Delta_{2, r}\left(\theta_{2}^{j}, n_{2, n r}^{j}\left(\theta_{2}\right), n_{2, r}^{\prime j}\left(\theta_{2}\right)\right) \leqslant$ $\left.\Delta_{2, r}\left(\theta_{2}^{j}, n_{2, n r}^{j}\left(\theta_{2}\right), n_{2, r}^{j}\left(\theta_{2}\right)\right)\right)$. Thus, the game between the agents satisfies strategic complementarities: an agent's incentive to run is higher if more agents run at each $\theta_{2}$. It is also easy to see that if $n_{2, r}^{j}\left(\theta_{2}\right)$ and $n_{2, n r}^{j}\left(\theta_{2}\right)$ are deterministic functions and are weakly decreasing, then, because $R\left(\theta_{2}, n\right)$ is increasing in $\theta_{2}, \Delta_{2, r}$ and $\Delta_{2, n r}$ are increasing in $\theta_{2}^{j}$. Functions $\Delta_{2, r}$ and $\Delta_{2, n r}$ are also continuous in $\theta_{2}^{j}$ since a small change in $\theta_{2}^{j}$ slightly shifts the interval over which the integrals are computed (and because $R$ is bounded).

We show that the equilibrium is unique by iterative dominance. We start with the belief that makes agents least willing to run: that all other agents never run (i.e., $\left.n_{2, n r}^{j}=n_{2, r}^{j}=0\right)$. By the assumption of a lower dominance region, we know that even for that belief, $\Delta_{2, r}$ and $\Delta_{2, n r}$ are negative for all $\theta_{2}^{j} \leqslant \varepsilon<\underline{\theta}-\varepsilon$. Thus, and since $\Delta_{2, r}$ and $\Delta_{2, n r}$ are increasing in $\theta_{2}^{j}$, there are thresholds $\theta_{2, r}^{1}>\varepsilon$ and $\theta_{2, n r}^{1}>\varepsilon$ such that agents run if they observe a signal below it and do not run if they observe a signal above it $\left(\theta_{2, r}^{1}\right.$ corresponds to agents who ran in country 1 and $\theta_{2, n r}^{1}$ to those who did not). Because of the strategic complementarities, we know that if agents run below these thresholds under the belief that others never run, then they must do so under any belief.

We now consider the belief that makes agents least willing to run among those beliefs that are consistent with the fact that they must run below $\theta_{2, r}^{1}$ and $\theta_{2, n r}^{1}$. This is the belief that they run below these thresholds and do not run above them. We obtain new thresholds, $\theta_{2, r}^{2}$ and $\theta_{2, n r}^{2}$ below which agents must run. These thresholds are higher than $\theta_{2, r}^{1}$ and $\theta_{2, n r}^{1}$, respectively, since they are computed using 
the higher functions $n_{2, r}^{j}$ and $n_{2, n r}^{j}$. We iterate this process ad infinitum and denote the limits by $\theta_{2, r}^{\infty}$ and $\theta_{2, n r}^{\infty}$. We know that agents run below these thresholds. Moreover, since the iteration stopped there, we know that under the belief that agents run below these thresholds and do not run above them, agents would not run above them.

We now start an iterative process from above; this time, however, we work with a translation of the pair $\left(\theta_{2, r}^{\infty}, \theta_{2, n r}^{\infty}\right)$. We start with the belief that makes agents most willing to run: that all other agents always run (i.e., $n_{2, r}^{j}=n_{1}$ and $n_{2, n r}^{j}=1-n_{1}$ ). Let $x^{1}$ be the smallest number such that, under this belief, agents who ran in country $1 \mathrm{do}$ not run above $\theta_{2, r}^{\infty}+x^{1}$, and agents who did not run in country 1 do not run above $\theta_{2, n r}^{\infty}+x^{1}$ (note that $x^{1}$ must be positive since we are using a belief that generates a higher incentive to run relative to the belief that determines $\theta_{2, r}^{\infty}$ and $\theta_{2, n r}^{\infty}$ ). Knowing that agents do not run above these thresholds, we can obtain a number $0<x^{2}<x^{1}$ such that agents do not run above $\theta_{2, r}^{\infty}+x^{2}$ and $\theta_{2, n r}^{\infty}+x^{2}$. We iterate this process ad infinitum and denote the limit of the sequence by $x^{\infty}$. We know that agents do not run above $\theta_{2, r}^{\infty}+x^{\infty}$ and $\theta_{2, n r}^{\infty}+x^{\infty}$. Moreover, because the iteration stopped there, we know that under the belief that agents run below these thresholds and do not run above them, it cannot be the case that there is a positive interval below each one of the thresholds in which agents do not run. This means that under this belief, either $\Delta_{2, r}=0$ at $\theta_{2, r}^{\infty}+x^{\infty}$ or $\Delta_{2, n r}=0$ at $\theta_{2, n r}^{\infty}+x^{\infty}$.

Suppose first that $\Delta_{2, r}=0$ at $\theta_{2, r}^{\infty}+x^{\infty}$. By the definition of $\Delta_{2, r}$, and since (by the existence of the upper dominance region) $\theta_{2, r}^{\infty}+x^{\infty}$ has to be below $1-\varepsilon$ (which implies that the posterior distribution of $\theta_{2}$ is uniformly distributed around the agent's signal), we have

$$
\begin{aligned}
& \int_{\theta_{2}=\theta_{2, r}^{\infty}+x^{\infty}-\varepsilon}^{\theta_{2, r}^{\infty}+x^{\infty}+\varepsilon}\left[u\left(1+R\left(\theta_{2},\left(n_{2, n r}\left(\theta_{2}, \theta_{2, n r}^{\infty}+x^{\infty}\right)+n_{2, r}\left(\theta_{2}, \theta_{2, r}^{\infty}+x^{\infty}\right)\right)\right)\right)\right. \\
& \quad-u(1+1)] d \theta_{2}=0,
\end{aligned}
$$

where $n_{2, r}\left(\theta_{2}, \theta^{\prime}\right)$ denotes the number of agents who ran in country 1 and decide to run in country 2 given that they run in country 2 below the signal $\theta^{\prime}$ and do not run above, and where $n_{2, n r}\left(\theta_{2}, \theta^{\prime}\right)$ is defined similarly. This can be rewritten as

$$
\int_{\tilde{\theta}_{2}=\theta_{2, r}^{\infty}, \varepsilon}^{\theta_{2, r}^{\infty}+\varepsilon}\left[u\left(1+R\left(\tilde{\theta}_{2}+x^{\infty},\left(n_{2, n r}\left(\tilde{\theta}_{2}, \theta_{2, n r}^{\infty}\right)+n_{2, r}\left(\tilde{\theta}_{2}, \theta_{2, r}^{\infty}\right)\right)\right)\right)-u(1+1)\right] d \tilde{\theta}_{2}=0 .
$$

But from the first iteration we know that an agent at $\theta_{2, r}^{\infty}$ is indifferent between running or not on the belief that others run below $\theta_{2, r}^{\infty}$ and $\theta_{2, n r}^{\infty}$, and do not run above them. Then, since (by the existence of the lower dominance region) $\theta_{2, r}^{\infty}$ must be above $\varepsilon$, we have

$$
\int_{\theta_{2}=\theta_{2, r}^{\infty}-\varepsilon}^{\theta_{2, r}^{\infty}+\varepsilon}\left[u\left(1+R\left(\theta_{2},\left(n_{2, n r}\left(\theta_{2}, \theta_{2, n r}^{\infty}\right)+n_{2, r}\left(\theta_{2}, \theta_{2, r}^{\infty}\right)\right)\right)\right)-u(1+1)\right] d \theta_{2}=0 .
$$


Since $R(\theta, n)$ is increasing in $\theta$, the two equations can be satisfied only if $x^{\infty}=0$. In a similar way, we can show that $x^{\infty}$ must also equal 0 if $\Delta_{2, n r}=0$ at $\theta_{2, n r}^{\infty}+x^{\infty}$. This means that the limits of the iterations from above and from below coincide. Hence, there is a unique equilibrium in which agents who ran in country 1 run if they observe a signal below $\theta_{2, r}^{\infty}$ and do not run above, and agents who did not run in country 1 run if they observe a signal below $\theta_{2, n r}^{\infty}$ and do not run above.

Proof of Lemma 1. Suppose that $\theta_{2, r}^{*}-\theta_{2, n r}^{*}>2 \varepsilon$. Then, an agent who ran in country 1 and observes $\theta_{2, r}^{*}$ in country 2 believes that all the agents who did not run in country 1 will not run in country 2 . This agent is also indifferent between her two options in country 2. Thus, $\Delta_{2, r}\left(\theta_{2, r}^{*}, 0, n_{2, r}\left(\theta_{2}, \theta_{2, r}^{*}\right)\right)=0$. Because the long-term return $R\left(\theta_{2}, n_{2}\right)$ on the investment in country 2 is increasing in $\theta_{2}$ and decreasing in $n_{2}$, a necessary condition for this equation to hold is that $R\left(\theta_{2, r}^{*}-\varepsilon, n_{1}\right)$ be lower than 1 . Now consider an agent who did not run in country 1 and observes $\theta_{2, n r}^{*}$. She believes that all the agents who ran in country 1 will run in country 2 . This agent is also indifferent between her two options in country 2. Thus, $\Delta_{2, n r}\left(\theta_{2, n r}^{*}, n_{2, n r}\left(\theta_{2}, \theta_{2, n r}^{*}\right), n_{1}\right)=0$. A necessary condition for this equation to hold is that $R\left(\theta_{2, n r}^{*}+\varepsilon, n_{1}\right)$ be higher than 1 . However, since $\theta_{2, r}^{*}-\theta_{2, n r}^{*}>2 \varepsilon$, this requirement contradicts the former - that $R\left(\theta_{2, r}^{*}-\varepsilon, n_{1}\right)$ be lower than 1 . Similarly, one can show that $\theta_{2, n r}^{*}-\theta_{2, r}^{*}$ cannot be higher than $2 \varepsilon$.

Proof of Proposition 2. Let $n_{1}^{\varepsilon}\left(\theta_{1}, \tilde{\theta}_{1}\right)$ denote the proportion of agents who run in country 1 as a function of $\theta_{1}$, given that each agent runs in that country if she observes a signal below $\tilde{\theta}_{1}$ and does not run above it (the index $\varepsilon$ appears so as to make the dependence explicit). Let $\Delta_{1}^{\varepsilon}\left(\theta_{1}, \tilde{\theta}_{1}\right)$ denote the difference between the utility that an agent expects to attain in the case that she keeps her investment in country 1 until it matures and the utility she expects to attain if she withdraws early, when she observes the signal $\theta_{1}$ and has the belief $n_{1}^{\varepsilon}\left(\theta_{1}, \tilde{\theta}_{1}\right)$. A threshold equilibrium then exists in country 1 if there is some $\tilde{\theta}_{1}$, such that $\Delta_{1}^{\varepsilon}\left(\tilde{\theta}_{1}, \tilde{\theta}_{1}\right)=0$ and $\Delta_{1}^{\varepsilon}\left(\theta_{1}^{\prime}, \tilde{\theta}_{1}\right)<(>) 0$ for any $\theta_{1}^{\prime}<(>) \tilde{\theta}_{1}$.

Consider the expression for $\Delta_{1}^{\varepsilon}\left(\tilde{\theta}_{1}, \tilde{\theta}_{1}\right)$ :

$$
\begin{aligned}
\Delta_{1}^{\varepsilon}\left(\tilde{\theta}_{1}, \tilde{\theta}_{1}\right)= & \frac{1}{2 \varepsilon} \int_{\theta_{1}=\tilde{\theta}_{1}-\varepsilon}^{\tilde{\theta}_{1}+\varepsilon} \int_{\theta_{2}=0}^{1} \frac{1}{2 \varepsilon} \int_{\theta_{2}^{j}=\theta_{2}-\varepsilon}^{\theta_{2}+\varepsilon} \\
& {\left[\begin{array}{c}
u\left(R\left(\theta_{1}, n_{1}^{\varepsilon}\left(\theta_{1}, \tilde{\theta}_{1}\right)\right)+w_{2, n r}^{\varepsilon}\left(\theta_{1}, n_{1}^{\varepsilon}\left(\theta_{1}, \tilde{\theta}_{1}\right) ; \theta_{2}, \theta_{2}^{j}\right)\right) \\
-u\left(1+w_{2, r}^{\varepsilon}\left(\theta_{1}, n_{1}^{\varepsilon}\left(\theta_{1}, \tilde{\theta}_{1}\right) ; \theta_{2}, \theta_{2}^{j}\right)\right)
\end{array}\right] d \theta_{2}^{j} d \theta_{2} d \theta_{1}, }
\end{aligned}
$$


where $w_{2, n r}^{e}$ and $w_{2, r}^{e}$ denote the returns in country 2 (see Eqs. (2) and (3) in Section 3). By Lemma $1, w_{2, n r}^{\varepsilon}$ and $w_{2, r}^{\varepsilon}$ are the same for all $\theta_{2}$, except for an interval with measure no more than $4 \varepsilon$. Thus, for small enough $\varepsilon$, this expression must be positive when $\tilde{\theta}_{1}$ is high enough (so that agents know the fundamentals in country 1 are in the upper dominance region), and negative when $\tilde{\theta}_{1}$ is low enough (so that agents know the fundamentals in country 1 are in the lower dominance region). Finally, $\Delta_{1}^{\varepsilon}\left(\tilde{\theta}_{1}, \tilde{\theta}_{1}\right)$ is continuous in $\tilde{\theta}_{1}$ since a small change in $\tilde{\theta}_{1}$ only slightly shifts the interval over which $\theta_{1}$ ranges, and since the integrand is continuous in $\tilde{\theta}_{1}$ and bounded (note that a small change in $n_{1}^{\varepsilon}\left(\theta_{1}, \tilde{\theta}_{1}\right)$ leads to a small change in the threshold signals of country $2)$. This shows that there exists some $\tilde{\theta}_{1}$ at which $\Delta_{1}^{\varepsilon}\left(\tilde{\theta}_{1}, \tilde{\theta}_{1}\right)=0$. Assume now that $\theta_{1}^{*}$ satisfies $\Delta_{1}^{\varepsilon}\left(\theta_{1}^{*}, \theta_{1}^{*}\right)=0$ and assume that $\theta_{1}^{\prime}<\theta_{1}^{*}$. We will show that $\Delta_{1}^{\varepsilon}\left(\theta_{1}^{\prime}, \theta_{1}^{*}\right)<0$. (The proof that $\Delta_{1}^{\varepsilon}\left(\theta_{1}^{\prime}, \theta_{1}^{*}\right)>0$ for $\theta_{1}^{\prime}>\theta_{1}^{*}$ is analogous.)

Denote $c=\left[\theta_{1}^{*}-\varepsilon, \theta_{1}^{*}+\varepsilon\right] \cap\left[\theta_{1}^{\prime}-\varepsilon, \theta_{1}^{\prime}+\varepsilon\right]$ and $d^{\prime}=\left[\theta_{1}^{\prime}-\varepsilon, \theta_{1}^{\prime}+\varepsilon\right] \backslash c$. Then:

$$
\begin{aligned}
\Delta_{1}^{\varepsilon}\left(\theta_{1}^{\prime}, \theta_{1}^{*}\right)= & \frac{1}{2 \varepsilon} \int_{\theta_{1} \in c} \int_{\theta_{2}=0}^{1} \frac{1}{2 \varepsilon} \int_{\theta_{2}^{j}=\theta_{2}-\varepsilon}^{\theta_{2}+\varepsilon}\left[\begin{array}{c}
u\left(R\left(\theta_{1}, n_{1}^{\varepsilon}\left(\theta_{1}, \theta_{1}^{*}\right)\right)+w_{2, n r}^{\varepsilon}\left(\theta_{1}, n_{1}^{\varepsilon}\left(\theta_{1}, \theta_{1}^{*}\right) ; \theta_{2}, \theta_{2}^{j}\right)\right) \\
-u\left(1+w_{2, r}^{\varepsilon}\left(\theta_{1}, n_{1}^{\varepsilon}\left(\theta_{1}, \theta_{1}^{*}\right) ; \theta_{2}, \theta_{2}^{j}\right)\right)
\end{array}\right] d \theta_{2}^{j} d \theta_{2} d \theta_{1} \\
& +\frac{1}{2 \varepsilon} \int_{\theta_{1} \in d^{\prime}} \int_{\theta_{2}=0}^{1} \frac{1}{2 \varepsilon} \int_{\theta_{2}^{\prime}=\theta_{2}-\varepsilon}^{\theta_{2}+\varepsilon}\left[\begin{array}{c}
u\left(R\left(\theta_{1}, 1\right)+w_{2, n r}^{\varepsilon}\left(\theta_{1}, 1 ; \theta_{2}, \theta_{2}^{j}\right)\right) \\
-u\left(1+w_{2, r}^{\varepsilon}\left(\theta_{1}, 1 ; \theta_{2}, \theta_{2}^{j}\right)\right)
\end{array}\right] d \theta_{2}^{j} d \theta_{2} d \theta_{1}
\end{aligned}
$$

Since $\Delta_{1}^{\varepsilon}\left(\theta_{1}^{*}, \theta_{1}^{*}\right)=0$, we know that $\theta_{1}^{*}-\varepsilon$ must be below the upper dominance region. This implies that for all $\theta_{1} \in d^{\prime}, R\left(\theta_{1}, 1\right)<1$. Thus, for small enough $\varepsilon$ (such that $w_{2, n r}^{\varepsilon}$ and $w_{2, r}^{\varepsilon}$ are the same for almost all $\theta_{2}$ ) the second component must be negative.

To see why the first component is negative, consider the value of $R$ at the highest point in $c: R\left(\theta_{1}^{\prime}+\varepsilon, n_{1}^{\varepsilon}\left(\theta_{1}^{\prime}+\varepsilon, \theta_{1}^{*}\right)\right)$. If it is less than or equal to 1 , then $R$ must be less than 1 at any point in $c$. Since the derivatives of $R$ are bounded away from 0 , then for small enough $\varepsilon$ the effect of the difference between $w_{2, n r}^{\varepsilon}$ and $w_{2, r}^{\varepsilon}$ is negligible and the integrand is negative for all $\theta_{1} \in c$, implying that the first component is negative. Now, using a similar argument, if $R\left(\theta_{1}^{\prime}+\varepsilon, n_{1}^{\varepsilon}\left(\theta_{1}^{\prime}+\varepsilon, \theta_{1}^{*}\right)\right)>1$, then for small enough $\varepsilon$ we must have

$$
I\left(\theta_{1}\right)=\int_{\theta_{2}=0}^{1} \int_{\theta_{2}^{j}=\theta_{2}-\varepsilon}^{\theta_{2}+\varepsilon}\left[\begin{array}{c}
u\left(R\left(\theta_{1}, n_{1}^{\varepsilon}\left(\theta_{1}, \theta_{1}^{*}\right)\right)+w_{2, n r}^{\varepsilon}\left(\theta_{1}, n_{1}^{\varepsilon}\left(\theta_{1}, \theta_{1}^{*}\right) ; \theta_{2}, \theta_{2}^{j}\right)\right) \\
-u\left(1+w_{2, r}^{\varepsilon}\left(\theta_{1}, n_{1}^{\varepsilon}\left(\theta_{1}, \theta_{1}^{*}\right) ; \theta_{2}, \theta_{2}^{j}\right)\right)
\end{array}\right] d \theta_{2}^{j} d \theta_{2}>0
$$

for all $\theta_{1} \in d^{*}=\left[\theta_{1}^{*}-\varepsilon, \theta_{1}^{*}+\varepsilon\right] \backslash c$. This implies that $\int_{d^{*}} I\left(\theta_{1}\right)>0$. As a result, and since $\Delta_{1}^{\varepsilon}\left(\theta_{1}^{*}, \theta_{1}^{*}\right)=\int_{c} I\left(\theta_{1}\right)+\int_{d^{*}} I\left(\theta_{1}\right)=0$, we must have that our first component, $\int_{c} I\left(\theta_{1}\right)$, is negative.

Proof of Theorem 1. Denote the two groups of agents corresponding to $n_{1}$ and $\theta_{1}$ by "rich" and "poor", where the rich are those with higher wealth from their country 1 
operations. It is easy to see that the threshold $\theta_{2 \text {,rich }}^{*}$ is below the threshold $\theta_{2, \text { poor }}^{*}$. If it were above, then a rich agent observing $\theta_{2 \text {,poor }}^{*}$ would strictly prefer to wait. This is because she has the same belief over the distribution of the number of agents who run as a poor agent who would have observed that signal. Since the poor agent is indifferent at that signal and because of decreasing absolute risk aversion, the richer agent must strictly prefer the risky prospect. Using the same logic, when agents from the two groups have the same level of wealth, they will have the same threshold signal.

Now the distribution of wealth corresponding to $n_{1}^{\prime}$ and $\theta_{1}^{\prime}$ first-order stochastically dominates the distribution corresponding to $n_{1}$ and $\theta_{1}$. This means that the shift from the latter distribution to the former can be decomposed into some steps (maybe one), where in each step we either increase the wealth of the rich group, or increase the wealth of the poor group, or move agents from the poor group to the rich group (assuming that the two have different levels of wealth). We show that, each one of these steps results in a decrease in the two thresholds $\theta_{2, \text { rich }}^{*}$ and $\theta_{2 \text {,poor }}^{*}$. To do this, we eliminate all the other possibilities.

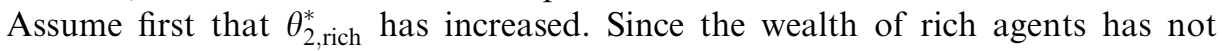
decreased, and since they are now indifferent at a higher signal, it must be that at the new threshold their belief over the number of agents who run in country 2 (in the new equilibrium) is above that corresponding to the old threshold (and old equilibrium). However, since the size of the rich group has not decreased, it must be that they believe that a higher proportion of the poor group are now running. This must mean that $\theta_{2 \text {,poor }}^{*}$ has increased by even more than the increase in $\theta_{2 \text {,rich. }}^{*}$ (Note that the distribution of the proportion of rich agents who run is unchanged.) But now consider a poor agent at the new threshold. She observes a higher signal than before, her wealth has not decreased and her belief over the number of agents who run in country 2 has become lower-both because the size of the rich group has not decreased and because $\theta_{2 \text {,rich }}^{*}$ has increased by less than $\theta_{2 \text {,poor }}^{*}$ (note that her distribution over the proportion of poor agents who run is unchanged). Thus, she must now strictly prefer to wait, in contradiction to the fact that she must be indifferent at her threshold.

A symmetric argument shows that $\theta_{2 \text {,poor }}^{*}$ must not have increased either. Now assume that both thresholds have not changed. If the wealth of agents from one group had increased, they would have had a higher incentive to wait. The incentive would move in the same direction if more agents belonged to the rich group which has a lower threshold. Thus, at least one group is no longer indifferent.

To conclude the proof, we claim that if one threshold had decreased, then the second would have also. To see why, note that in such a case an agent from the other group who observes her old threshold would have a lower distribution over the number of agents who run. A change in the size of the groups will only contribute to the decrease in the distribution. Since the wealth of her group has not decreased, the only way she can remain indifferent is if her signal is lower. 
Lemma 2. As \& approaches 0 , both $\theta_{2, r}^{*}$ and $\theta_{2, n r}^{*}$ converge to $\theta_{2}^{*}$, which is implicitly defined by the following two equations (with unknowns $\theta_{2}^{*}$ and $x$ ):

$$
\begin{aligned}
0= & E_{\theta_{2} \sim U\left[\theta_{2}^{*}-1, \theta_{2}^{*}+1\right]}\left[u\left(1+R\left(\theta_{2}^{*},\left(\left(1-n_{1}\right) \cdot n\left(\theta_{2}, \theta_{2}^{*}+x\right)+n_{1} \cdot n\left(\theta_{2}, \theta_{2}^{*}\right)\right)\right)\right)-u(1+1)\right], \\
0= & E_{\theta_{2} \sim U\left[\theta_{2}^{*}+x-1, \theta_{2}^{*}+x+1\right]} \\
& \times\left[u\left(R\left(\theta_{1}, n_{1}\right)+R\left(\theta_{2}^{*},\left(\left(1-n_{1}\right) \cdot n\left(\theta_{2}, \theta_{2}^{*}+x\right)+n_{1} \cdot n\left(\theta_{2}, \theta_{2}^{*}\right)\right)\right)\right)-u\left(R\left(\theta_{1}, n_{1}\right)+1\right)\right],
\end{aligned}
$$

where

$$
n\left(\theta_{2}, z\right)=\left\{\begin{array}{clc}
1 & \text { if } & z-1>\theta_{2} \\
\frac{z+1-\theta_{2}}{2} & \text { if } & z+1 \geqslant \theta_{2} \geqslant z-1 \\
0 & \text { if } & \theta_{2}>z+1
\end{array}\right.
$$

Proof. The equations that define the equilibrium for positive $\varepsilon$ are

$$
\begin{aligned}
0= & E_{\theta_{2} \sim U\left[\theta_{2, r}^{*}-\varepsilon, \theta_{2, r}^{*}+\varepsilon\right]}\left[u\left(1+R\left(\theta_{2},\left(n_{2, n r}\left(\theta_{2}, \theta_{2, n r}^{*}\right)+n_{2, r}\left(\theta_{2}, \theta_{2, r}^{*}\right)\right)\right)\right)-u(1+1)\right], \\
0= & E_{\theta_{2} \sim U\left[\theta_{2, n r}^{*}-\varepsilon, \theta_{2, n r}^{*}+\varepsilon\right]} \\
& \times\left[u\left(R\left(\theta_{1}, n_{1}\right)+R\left(\theta_{2},\left(n_{2, n r}\left(\theta_{2}, \theta_{2, n r}^{*}\right)+n_{2, r}\left(\theta_{2}, \theta_{2, r}^{*}\right)\right)\right)\right)-u\left(R\left(\theta_{1}, n_{1}\right)+1\right)\right] .
\end{aligned}
$$

Denoting $\theta_{2, r}^{*}=\theta_{2}^{*}, \theta_{2, n r}^{*}=\theta_{2}^{*}+x \cdot \varepsilon$ and

$$
n^{\varepsilon}\left(\theta_{2}, z\right)=\left\{\begin{array}{lll}
1 & \text { if } & z-\varepsilon>\theta_{2}, \\
\frac{z+\varepsilon-\theta_{2}}{2 \varepsilon} & \text { if } \quad z+\varepsilon \geqslant \theta_{2} \geqslant z-\varepsilon, \\
0 & \text { if } \quad \theta_{2}>z+\varepsilon,
\end{array}\right.
$$

we obtain

$$
\begin{aligned}
0= & E_{\theta_{2} \sim U\left[\theta_{2}^{*}-\varepsilon, \theta_{2}^{*}+\varepsilon\right]}\left\lfloor u\left(1+R\left(\theta_{2},\left(\left(1-n_{1}\right) \cdot n^{\varepsilon}\left(\theta_{2}, \theta_{2}^{*}+x \cdot \varepsilon\right)+n_{1} \cdot n^{\varepsilon}\left(\theta_{2}, \theta_{2}^{*}\right)\right)\right)\right)-u(1+1)\right\rfloor, \\
0= & E_{\theta_{2} \sim U\left[\theta_{2}^{*}+x \cdot \varepsilon-\varepsilon, \theta_{2}^{*}+x \cdot \varepsilon+\varepsilon\right]} \\
& \times\left\lfloor u\left(R\left(\theta_{1}, n_{1}\right)+R\left(\theta_{2},\left(\left(1-n_{1}\right) \cdot n^{\varepsilon}\left(\theta_{2}, \theta_{2}^{*}+x \cdot \varepsilon\right)+n_{1} \cdot n^{\varepsilon}\left(\theta_{2}, \theta_{2}^{*}\right)\right)\right)\right)-u\left(R\left(\theta_{1}, n_{1}\right)+1\right)\right\rfloor
\end{aligned}
$$

Because $R$ is continuous in the first argument and in the second, then for small $\varepsilon$ the solution $\left(\theta_{2}^{*}, x\right)$ is close to that of:

$$
\begin{aligned}
0= & E_{\theta_{2} \sim U\left[\theta_{2}^{*}-\varepsilon, \theta_{2}^{*}+\varepsilon\right]}\left\lfloor u\left(1+R\left(\theta_{2}^{*},\left(\left(1-n_{1}\right) \cdot n^{\varepsilon}\left(\theta_{2}, \theta_{2}^{*}+x \cdot \varepsilon\right)+n_{1} \cdot n^{\varepsilon}\left(\theta_{2}, \theta_{2}^{*}\right)\right)\right)\right)-u(1+1)\right\rfloor, \\
0= & E_{\theta_{2} \sim U\left[\theta_{2}^{*}+x \cdot \varepsilon-\varepsilon, \theta_{2}^{*}+x \cdot \varepsilon+\varepsilon\right]} \\
& \times\left\lfloor u\left(R\left(\theta_{1}, n_{1}\right)+R\left(\theta_{2}^{*},\left(\left(1-n_{1}\right) \cdot n^{\varepsilon}\left(\theta_{2}, \theta_{2}^{*}+x \cdot \varepsilon\right)+n_{1} \cdot n^{\varepsilon}\left(\theta_{2}, \theta_{2}^{*}\right)\right)\right)-u\left(R\left(\theta_{1}, n_{1}\right)+1\right)\right\rfloor .\right.
\end{aligned}
$$

Replacing $n^{\varepsilon}\left(\theta_{2}, z\right)$ with $n\left(\theta_{2}, z\right)$, we obtain the equations in the statement of the Lemma. 


\section{References}

[1] F. Allen, D. Gale, Financial contagion, J. Polit. Economy 108 (2000) 1-33.

[2] M.D. Bordo, B. Eichengreen, D.A. Irwin, Is globalization today really different than globalization a hundred years ago, Working Paper No. 7195, NBER, 1999.

[3] G. Calvo, Contagion in emerging markets: when Wall Street is a carrier, Working Paper, University of Maryland, 1999.

[4] G. Calvo, E. Mendoza, Rational contagion and the globalization of securities markets, J. Int. Econ. 51 (2000) 79-113.

[5] F. Caramazza, L. Ricci, R. Salgado, Trade and financial contagion in currency crises, Working Paper 00-55, International Monetary Fund, 2000.

[6] H. Carlsson, E. van Damme, Global games and equilibrium selection, Econometrica 61 (1993) 989-1018.

[7] Y. Chen, Banking Panics: the role of the first-come, first-served rule and information externalities, J. Polit. Economy 107 (1999) 946-968.

[8] G. Corsetti, A. Dasgupta, S. Morris, H.S. Shin, Does one Soros make a difference? The role of a large trader in currency crises, Rev. Econ. Stud. 71 (2004) 87-114.

[9] D. Cuoco, R. Kaniel, Equilibrium prices in the presence of delegated portfolio management, Working paper, University of Pennsylvania, 2002.

[10] J. Danielsson, J.P. Zigrand, What happens when you regulate risk? Evidence from a simple equilibrium model, Working paper, London School of Economics, 2002.

[11] A. Dasgupta, Financial contagion through capital connections: a model of the origin and spread of bank panics, Working paper, London School of Economics, 2002.

[12] D.W. Diamond, P.H. Dybvig, Bank runs, deposit insurance, and liquidity, J. Polit. Economy 91 (1983) 401-419.

[13] D. Frankel, S. Morris, A. Pauzner, Equilibrium selection in global games with strategic complementarities, J. Econ. Theory 108 (2003) 1-44.

[14] I. Goldstein, Strategic complementarities and the twin crises, Econ. J. (2005), forthcoming.

[15] I. Goldstein, A. Pauzner, Demand deposit contracts and the probability of bank runs, J. Finance (2005), forthcoming.

[16] R. Gordon, A. Lans Bovenberg, Why is capital so immobile internationally? Possible explanations and implications for capital income taxation, Amer. Econ. Rev. 86 (1996) 1057-1075.

[17] S.J. Grossman, Z. Zhou, Equilibrium analysis of portfolio insurance, J. Finance 51 (1996) 1379-1403.

[18] P. Jorion, Value at Risk: the new benchmark for managing financial risk, McGraw-Hill, New York, 2001.

[19] G.L. Kaminsky, R. Lyons, S. Schmukler, Mutual fund investment in emerging markets: an overview, World Bank Econ. Rev. 15 (2001) 315-340.

[20] G.L. Kaminsky, R. Lyons, S. Schmukler, Managers, investors, and crises: investment strategies of mutual funds, J. Int. Econ., (2004), forthcoming.

[21] G.L. Kaminsky, C.M. Reinhart, On crises, contagion, and confusion, J. Int. Econ. 51 (2000) 145-168.

[22] M. King, S. Wadhwani, Transmission of volatility between stock markets, Rev. Finan. Stud. 3 (1990) $5-33$.

[23] L.E. Kodres, M. Pritsker, A rational expectations model of financial contagion, J. Finance 57 (2002) 769-799.

[24] P. Krugman, Balance sheets, the transfer problem, and financial crises, in: P. Isard, A. Razin, A.K. Rose (Eds.), International Finance and Financial Crises, Kluwer Academic Publishers, Dordrecht, 2000 .

[25] A.S. Kyle, W. Xiong, Contagion as a wealth effect, J. Finance 56 (2001) 1401-1440.

[26] R. Lagunoff, S.L. Schreft, Financial fragility with rational and irrational exuberance, J. Money, Credit, Banking 31 (1999) 531-560.

[27] P. Masson, Contagion: monsoonal effects, spillovers, and jumps between multiple equilibria, Working Paper No. 98-142, International Monetary Fund, 1998. 
[28] S. Morris, H.S. Shin, Unique equilibrium in a model of self-fulfilling currency attacks, Amer. Econ. Rev. 88 (1998) 587-597.

[29] S. Morris, H.S. Shin, Rethinking multiple equilibria in macroeconomics, NBER Macroeconomics Annual, 2000.

[30] S. Morris, H.S. Shin, Global games: theory and applications, In: M. Dewatripont, L.P. Hansen, S.J. Turnovsky (Eds.), Advances in Economics and Econometrics, Cambridge University Press, Cambridge, 2003.

[31] S. Morris, H.S. Shin, Coordination risk and the price of debt, Europ. Econ. Rev. 48 (2004) $133-153$.

[32] M. Obstfeld, Models of currency crises with self-fulfilling features, Europ. Econ. Rev. 40 (1996) 1037-1047.

[33] H. Ou-Yang, An equilibrium model of asset pricing and moral hazard, Working paper, Duke University, 2002.

[34] S. Radelet, J.D. Sachs, The East Asian financial crisis: diagnosis, remedies, prospects, Brookings Pap. Econ. Act. 1 (1998) 1-74.

[35] R. Rigobon, The curse of non-investment grade countries, J. Devel. Econ. 69 (2002) 423-449.

[36] J. Rochet, X. Vives, Coordination failures and the lender of last resort: was Bagehot right after all, Working paper, INSEAD, 2003.

[37] G.J. Schinasi, R.T. Smith, Portfolio diversification, leverage, and financial contagion, IMF Staff Pap. 47 (2000) 159-176.

[38] C. Van Rijckeghem, B. Weder, Spillovers through banking centers: a panel data analysis, Working Paper No. 00-88, International Monetary Fund, 2000.

[39] C. Van Rijckeghem, B. Weder, Sources of contagion: is it finance or trade, J. Int. Econ. 54 (2001) 293-308.

[40] D. Vayanos, Flight to quality, flight to liquidity, and the pricing of risk, Working paper, MIT, 2002. 